\title{
Worldwide Status of CCUS Technologies and Their Development and Challenges in China
}

\author{
H. J. Liu, ${ }^{1}$ P. Were, ${ }^{2}$ Q. Li, ${ }^{3}$ Y. Gou, ${ }^{2,4}$ and Z. Hou ${ }^{2,4,5}$ \\ ${ }^{1}$ INRS-ETE, Universite du Québec, Québec, QC, Canada \\ ${ }^{2}$ Energie-Forschungszentrum Niedersachsen, Clausthal University of Technology, Goslar, Germany \\ ${ }^{3}$ State Key Laboratory of Geomechanics and Geotechnical Engineering, Institute of Rock and Soil Mechanics, \\ Chinese Academy of Sciences, Wuhan, China \\ ${ }^{4}$ Sino-German Energy Research Center, Sichuan University, Chengdu, China \\ ${ }^{5}$ Institute of Petroleum Engineering, Clausthal University of Technology, Clausthal-Zellerfeld, Germany \\ Correspondence should be addressed to Y. Gou; yang.gou@efzn.de and Z.Hou; hou@tu-clausthal.de
}

Received 19 February 2017; Revised 12 May 2017; Accepted 20 June 2017; Published 28 August 2017

Academic Editor: Weon Shik Han

Copyright (c) 2017 H. J. Liu et al. This is an open access article distributed under the Creative Commons Attribution License, which permits unrestricted use, distribution, and reproduction in any medium, provided the original work is properly cited.

\begin{abstract}
Carbon capture, utilization, and storage (CCUS) is a gas injection technology that enables the storage of $\mathrm{CO}_{2}$ underground. The aims are twofold, on one hand to reduce the emissions of $\mathrm{CO}_{2}$ into the atmosphere and on the other hand to increase oil/gas/heat recovery. Different types of CCUS technologies and related engineering projects have a long history of research and operation in the USA. However, in China they have a short development period ca. 10 years. Unlike $\mathrm{CO}_{2}$ capture and $\mathrm{CO}_{2}$-EOR technologies that are already operating on a commercial scale in China, research into other CCUS technologies is still in its infancy or at the pilot-scale. This paper first reviews the status and development of the different types of CCUS technologies and related engineering projects worldwide. Then it focuses on their developments in China in the last decade. The main research projects, international cooperation, and pilot-scale engineering projects in China are summarized and compared. Finally, the paper examines the challenges and prospects to be experienced through the industrialization of CCUS engineering projects in China. It can be concluded that the CCUS technologies have still large potential in China. It can only be unlocked by overcoming the technical and social challenges.
\end{abstract}

\section{Introduction}

Fossil fuels, especially coal that is rich in carbon, constitute the highest proportion of primary energy in China [1]. In recent years, the rapid urbanization and development of industries including power plants, cement factories, steel plants, biotransformation, and fossil fuel transformation plants, which are highly dependent on large consumption of fossil fuels, have been a great challenge to the Chinese environment [2,3]. Since the winter of 2012/2013, most cities in China have been faced with serious atmospheric pollution from a haze formed from a combination of $\mathrm{SO}_{2}$, NOx, and inhalable particles within the mist, containing fine particle concentrations of up to ca. $900 \mu \mathrm{g} / \mathrm{m}^{3}$ [4]. Automobile exhausts, industrial emissions, waste incineration, and fugitive dust from construction sites are the main sources of the haze. Based on statistical data from Beijing, reported by
China Central Television (CCTV) in 2014, haze particles from automobile exhausts contributed $22.2 \%$, while the burning of coal, dust, and industrial emissions accounted for proportions of $16.7 \%, 16.3 \%$, and $15.7 \%$, respectively. Therefore, a reduction in the emissions from coal and industry has become the key to improving the quality of the environment.

The increase in the concentration of greenhouse gases has had a large impact on global climate change, since industrialization. Many countries have set targets for reducing the emissions of greenhouse gases in order to mitigate global warming. Among them, top on the list of $\mathrm{CO}_{2}$ emissions in the world, China aims at reducing $40 \%-45 \%$ of its $\mathrm{CO}_{2}$ emissions per unit GDP by 2020, based on the 2005 level [5-7]. This requires considerable changes not only in the framework of fossil fuel consumption, but also in the development of renewable energy from wind, solar, geothermal, and so on, together with an enlargement in the area covered by forests 
and innovations in technologies that can enable permanent storage of the $\mathrm{CO}_{2}$ underground.

$\mathrm{CO}_{2}$ emissions in China come mainly from the combustion of fossil fuels (90\%) and during the process of cement manufacturing (10\%). For example, in 2012, 68\% of the emitted $\mathrm{CO}_{2}$ was sourced mainly from the combustion of coal, while $13 \%$ came from oil and $7 \%$ from natural gas [8]. According to the statistics, annual emissions of $\mathrm{CO}_{2}$ from large stationary point sources, that is, $>0.1 \mathrm{Mt} /$ year, amount to $3.89 \mathrm{GtCO}_{2}$, which accounts for $67 \%$ of the total emissions. Among which, $72 \%$ is from power stations [9]. This demonstrates that a reduction of the $\mathrm{CO}_{2}$ emissions from the large stationary point sources is the key to realizing China's target $[10,11]$.

China's main target for the transformation in its energy framework is to reduce the combustion of coal, while increasing the supply of natural gas and other clean energy, and controlling the emissions of $\mathrm{CO}_{2}, \mathrm{SO}_{2}, \mathrm{NOx}$, and so on. $\mathrm{CO}_{2}$ capture and sequestration (CCS) and utilization (CCUS) technologies can be applied to store $\mathrm{CO}_{2}$ underground effectively, thus reducing its emission into the atmosphere. This technology is now highly developed and is likely to play a significant role in China, especially when the operation costs are reduced. This paper reviews the state of the art of CCS and CCUS technologies worldwide while paying more attention on its status and development in China. The mature technology will be examined in various engineering projects. Therefore, this paper considers the state of operation of CCS and CCUS projects in detail and concludes by presenting the likely challenges to be experienced through the industrialization of these projects in China. Due to space limitation, it has not been possible to include a review of the current research status on the conversion of $\mathrm{CO}_{2}$ to produce some commercial products or its use in the food industry, for example, as an additive in beverages or as a preservative for fruits and vegetables. Henceforth, only its utilization for geologic and geoengineering purposes such as EOR, ECBM, ESG, and EGR has been considered in this paper.

\section{Worldwide Development of CCS and CCUS}

The CCS technology is a means to control emissions of $\mathrm{CO}_{2}$ that are captured from different processes including precombustion, postcombustion, and oxy-fuel combustion. The stages of a CCS project can be divided into (1) $\mathrm{CO}_{2}$ capture, (2) $\mathrm{CO}_{2}$ transportation, (3) $\mathrm{CO}_{2}$ injection, and (4) postinjection of $\mathrm{CO}_{2}$ [12-19].

In the short term, depending on the purpose of the CCS project, $\mathrm{CO}_{2}$ can be stored in different geological sites, including deep saline formations, depleted oil or gas reservoirs, deep unmineable coal seams, and shale formations, to reduce the $\mathrm{CO}_{2}$ emissions [20,21], Figure 1. In comparison with the pure CCS technology, CCUS technology pays more attention to utilization $(\mathrm{U})$ of the captured $\mathrm{CO}_{2}$ while sequestration (S) plays a secondary role. CCUS can reduce the cost of sequestration and bring benefits by enhancing the production of hydrocarbons or heat energy, thus becoming very popular in recent years. Based on the purpose of the $\mathrm{CO}_{2}$ injection, a number of related technologies have been developed including (1) Enhanced Oil Recovery (EOR), (2) Enhanced Coalbed Methane Recovery (ECBM), (3) Enhanced Gas Recovery (EGR), (4) Enhanced Shale Gas Recovery (ESG), and (5) Enhanced Geothermal System (EGS).

The engineering projects for both CCS and CCUS technologies are systematically complicated, with their success depending on rigorous research in engineering and science disciplines including geology, geoengineering, geophysics, environmental engineering, mathematics, and computer sciences. In addition, key to success in site selection for any such a project demands strict considerations of safety, economy, environment, and public acceptance at all levels of operation, that is, countrywide, basin-wide, regional, or subbasin levels [22-26], Figure 2. Although CCS and CCUS technologies share similarities in site selection, each will induce a series of different physical and chemical responses in the underground porous or fractured rock formations, in terms of the existing local hydrological $(\mathrm{H})$, thermal $(\mathrm{T})$, mechanical $(\mathrm{M})$, and chemical (C) fields [27-29], Figure 2. Coupling of the THMC processes during and after $\mathrm{CO}_{2}$ injection related to CCS and CCUS technologies has become a research hotspot in recent years [26, 30-33]. The two technologies, however, have minor differences, in terms of purpose, storage duration, injection depth and rate, fluid and reservoir types, scheme of drilling, completion and monitoring, and so on.

2.1. CCS. CCS is a viable option for significantly reducing $\mathrm{CO}_{2}$ emissions from large-scale emission sources. When its only purpose is for $\mathrm{CO}_{2}$ sequestration, the storage sites may include deep saline formations, deep unmineable coal seam, depleted oil or gas reservoir, and rock salt caverns [3538]. This technology is mature but still very expensive for widespread commercial application.

2.2. CCUS: $\mathrm{CO}_{2}$-EOR. The first $\mathrm{CO}_{2}$-EOR field test was held in 1964 in Mead Strawn Texas, in the USA. Since the 1970s, $\mathrm{CO}_{2}$ has been used on a commercial scale for oil production projects [20,21]. Up to the present time, there have been more than $100 \mathrm{CO}_{2}$-EOR projects in operation. Among them, the $\mathrm{CO}_{2}$-EOR project in Weyburn, Canada, is the most successful example. It uses mixed gases separated from natural gas production, coal gasification, and coal power from the Great Plains Synfuels Plant near Beulah, North Dakota, USA [39]. The injection gas is mainly composed of $\mathrm{CO}_{2}(96.8 \%)$, plus $\mathrm{H}_{2} \mathrm{~S}(1.1 \%)$ and a minor amount of hydrocarbons that are piped to the Weyburn Basin through a pipeline $339 \mathrm{~km}$ in length [7]. The purpose of the project is to inject 2 million tons of $\mathrm{CO}_{2}$ into the depleting oil reservoir over a 20 -year period, in order to increase oil recovery to 130 million barrels and to extend the production of oil in this oilfield to 25 years [40].

2.3. CCUS: $\mathrm{CO}_{2}-E C B M$. The conventional method to produce coalbed methane is to decrease the pressure in the coalbed reservoir, making the methane desorb from the matrix. However, the recovery of coalbed methane production using this method is less than $50 \%$. The alternative is to desorb more $\mathrm{CH}_{4}$ from the coalbed matrix by injecting gases including $\mathrm{CO}_{2}$ or $\mathrm{N}_{2}$ [41-44]. Studies on enhancing 


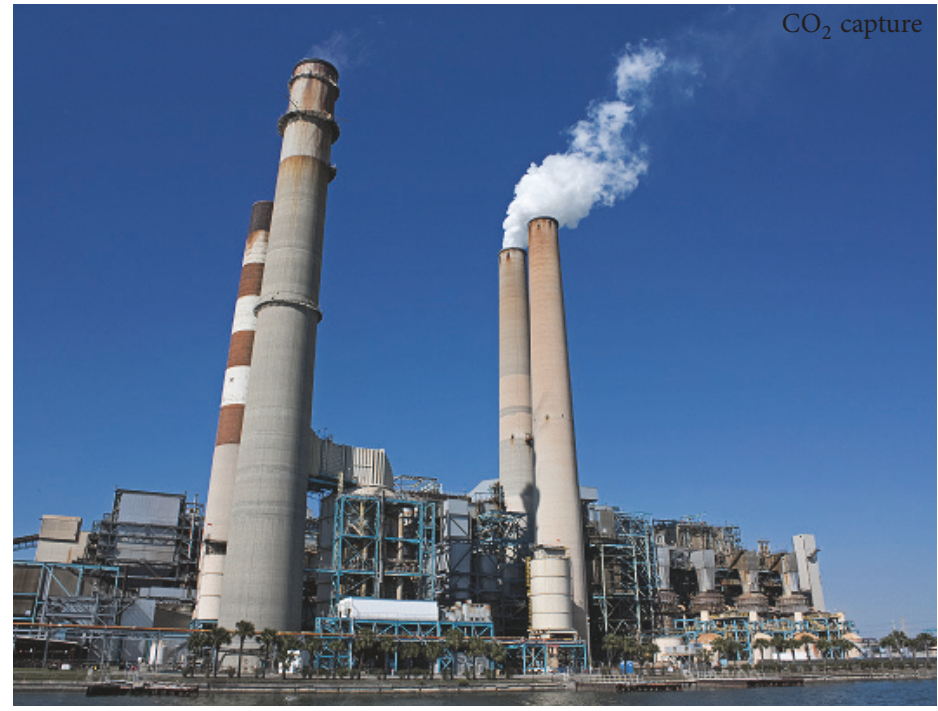

$\mathrm{CO}_{2}$ transport

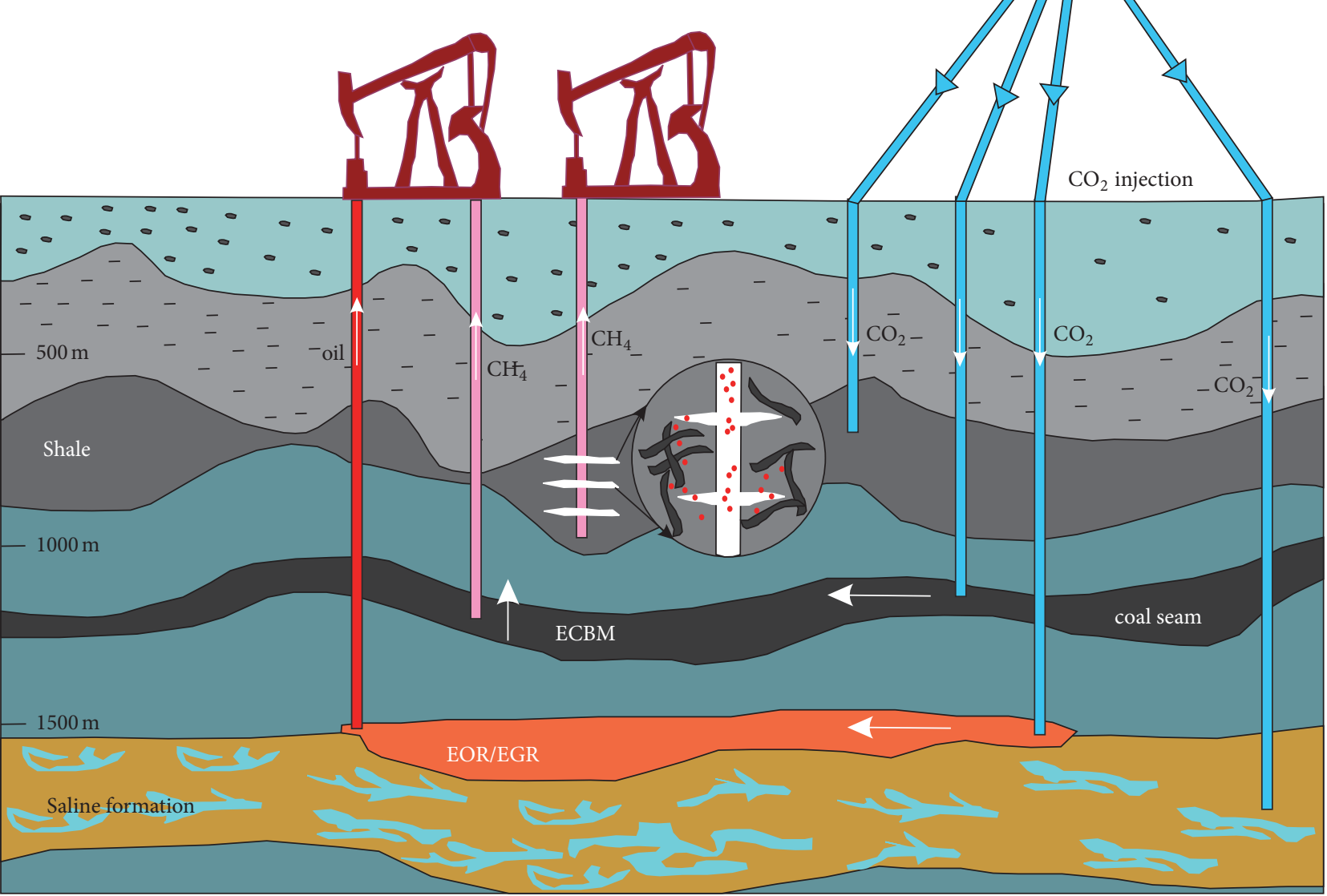

FIGURE 1: Schematic diagram of the CCUS technology in different geological reservoirs for both long and short-term sequestration of $\mathrm{CO}_{2}$.

coalbed methane by $\mathrm{CO}_{2}$ injection started in the 1990 s $[7,45]$. When $\mathrm{CO}_{2}$ is injected in the coalbed layer, both the gaseous and adsorbed-state of $\mathrm{CH}_{4}$ and $\mathrm{CO}_{2}$ will exist in equilibrium [46]. Because the coalbed has a much stronger adsorption capacity for $\mathrm{CO}_{2}$ than $\mathrm{CH}_{4}$, the injection of $\mathrm{CO}_{2}$ will make the adsorbed $\mathrm{CH}_{4}$ desorb, thus enhancing the $\mathrm{CH}_{4}$ recovery.
A proportion of the injected $\mathrm{CO}_{2}$ will be stored in the coalbed formation, making it difficult for it to leak to the surface. Therefore, this technology can bring both economic benefits and also guarantee the safe storage of $\mathrm{CO}_{2}[47,48]$.

The successful injection of $\mathrm{CO}_{2}$ to enhance coalbed methane recovery has been proved by many experimental 


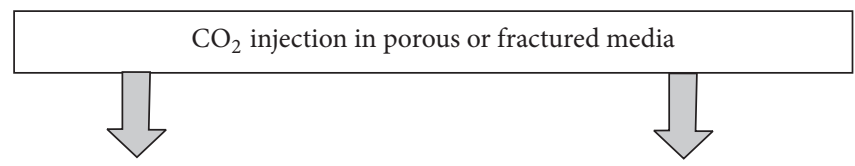

Topic 1: Site selection system

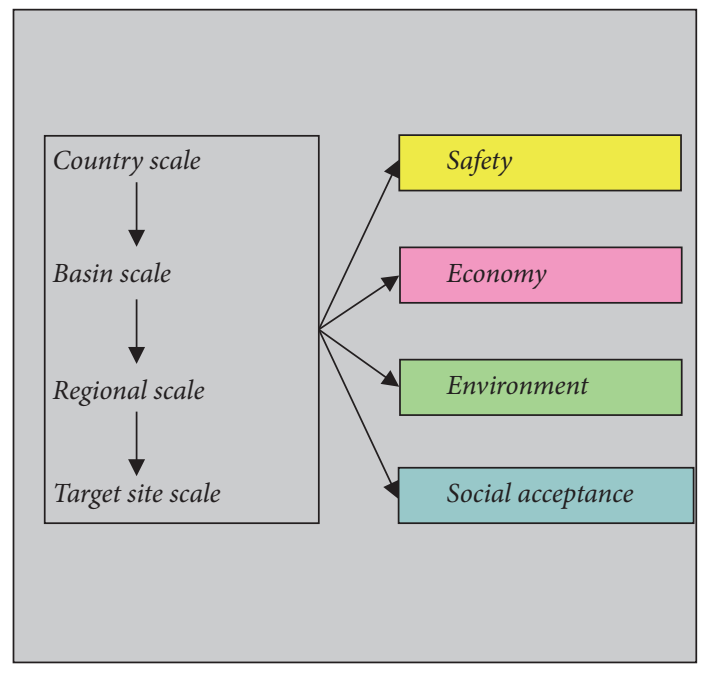

Topic 2: THMC response

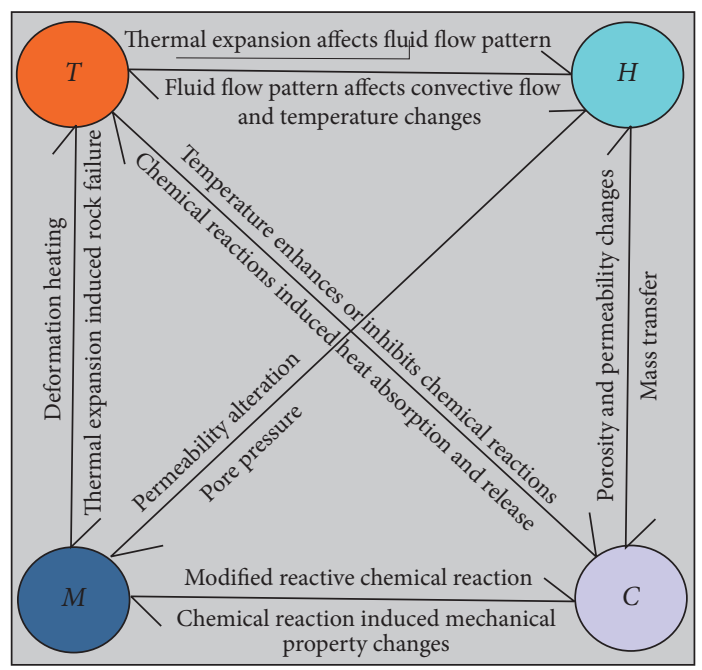

FIGURE 2: Schematics of the two main topics, that is, the site selection system (1) and the THMC responses (2) associated with CCS and CCUS technologies.

and numerical studies. However, the production efficiency is strongly site-dependent, in relation to the permeability of the coalbed matrix, production history, gas transportation process, maturation of coal, geological configuration, completion scheme, hydraulic pressure, and so on [4244, 49-52]. Nevertheless, the maturity of its commercial application is still very low. Pilot-scale $\mathrm{CO}_{2}$-ECBM projects so far include those in Alberta, Canada, which started in 1997, the Burlington project in the San Juan Basin of the USA, the RECOPOL project that started in 2001, the Yubari project in Japan, and the Qinshui basin project in China that started in 2002 [53].

2.4. CCUS: $\mathrm{CO}_{2}-E G R$. Studies on injecting $\mathrm{CO}_{2}$ into depleted gas reservoirs to enhance gas recovery started in the $1990 \mathrm{~s}$ [54]. Unlike the $\mathrm{CO}_{2}$-EOR technology, $\mathrm{CO}_{2}$-EGR technology is still at the pilot-scale stage. Its efficiency is highly dependent on reservoir type, temperature and pressure conditions, heterogeneity, production strategy, and so on [55-60]. For some $\mathrm{CO}_{2}$-EGR projects, the gas recovered can reach $10 \%$, while other projects have seen less or no enhancement [61-63]. The rapid breakthrough of $\mathrm{CO}_{2}$ in a production well, resulting in a high concentration of $\mathrm{CO}_{2}$, restricts the production of pure natural gas [64]. Since 1999, the USA has carried out a pilot project of $\mathrm{CO}_{2}$-EGR in Rio Vista. The Netherlands injected 60 kilotonnes of $\mathrm{CO}_{2}$ into a depleted gas reservoir in the K12B project during 2004 and 2009 [7]. The CLEAN project in Germany started a $\mathrm{CO}_{2}$-EGR project in the Altmark gas fields in 2009; however, public protests have prevented $\mathrm{CO}_{2}$ injection on the site [65]. Many other countries including Australia and Norway are also positively developing this technology [64, 66-74].
2.5. CCUS: $\mathrm{CO}_{2}$-ESG. The USA has been carrying out shale gas desorption since 1821. However, limited development of the technology made this process procedurally cumbersome and substantively difficult to apply before the 21st century. In 2000 , shale gas contributed only $1 \%$ of the whole natural gas supply, while, by the end of 2011, this proportion had increased to $30 \%$ due to a breakthrough in horizontal drilling and horizontal multistaged fracturing technology. The revolution of shale gas in the USA is changing the energy structure of the world [75].

Encouraged by the successful application of $\mathrm{CO}_{2}$ in oil and gas recovery, its application in aiding the production of shale gas began in recent years [76-81]. There has also been progress in replacing water by supercritical $\mathrm{CO}_{2}$ as the injection fluid in the fracturing technology [82-86]. However, this process is still in the very early exploration stages.

2.6. CCUS: $\mathrm{CO}_{2}$-EGS. The first study of EGS technology started in Fenton Hill, USA, in 1970 [87]. Since then, many other countries, including France, Germany, Austria, Italy, Japan, and Australia, have paid attention to the development of this technology. The conventional EGS technology uses water as the injection fluid and circulation media. Based on the research in [88], $\mathrm{CO}_{2}$ is now regarded as a more favorable circulation fluid compared with water because of its large compressibility and expansibility. This idea has already been supported by many studies (e.g., [89-93]).

The application of $\mathrm{CO}_{2}$ in a geothermal system is not restricted to the hot dry rock reservoirs but also includes the conventional hydrothermal reservoirs [38, 91, 94]. The injection of $\mathrm{CO}_{2}$ can enhance the efficiency of reinjecting the hot wastewater by improving the porosity and permeability 
through the activated water-rock geochemical reactions [95]. Besides being the main circulation fluid, $\mathrm{CO}_{2}$ can also be regarded as a pressurized hydraulic fluid in the reservoir. Injection of $\mathrm{CO}_{2}$ in a hydrothermal or hot dry rock reservoir can maintain the reservoir pressure, promoting the flow rate of the in situ water towards the production well, thus enhancing the heat recovery and even the recovery of the $\mathrm{CH}_{4}$ dissolved in the aquifer water [96-99]. Reference [38] described this process as the $\mathrm{CO}_{2}$-AGES $\left(\mathrm{CO}_{2}\right.$-aided geothermal extraction system) in which three stages are involved: (1) the production of hot water when $\mathrm{CO}_{2}$ is used as the pressurized hydraulic fluid; (2) two-phase fluid flow in the production well after the $\mathrm{CO}_{2}$ breakthrough; and (3) and as a circulation fluid, when $\mathrm{CO}_{2}$ fills the production well, which is similar to $\mathrm{CO}_{2}$-EGS.

\section{CCS and CCUS Engineering Projects Worldwide}

By the end of 2016, based on the statistics of Global Status 2016, there were 38 large-scale CCS + CCUS projects in operation or under construction and planning. Among them, 17 projects are located in North America (12 projects in the United States and 5 in Canada); 12 projects in Asia (8 in China, 2 in South Korea, 1 in Saudi Arabia, and 1 in United Arab Emirates), 5 in Europe ( 2 in Norway, 2 in United Kingdom, and 1 in the Netherlands), 3 in Australia, and 1 in Brazil. Among the 15 projects that are in operation, 12 projects are related to $\mathrm{CO}_{2}$-EOR and the other 3 projects are pure $\mathrm{CO}_{2}$ sequestration. There are 66 pilot-scale CCS + CCUS projects of which 22 are in operation, 5 under construction, 5 at the planning stage, and 34 have just been completed.

Among the 70 pilot-scale engineering CCUS projects worldwide, based on their distribution by regions or countries, 22 are located in North America, 1 in South America, 22 in Europe, 20 in Asia, 4 in Australia, and 1 in South Africa; see Figure 3 for more details.

There are still no concrete $\mathrm{CO}_{2}$-ESG and $\mathrm{CO}_{2}$-EGS projects anywhere in the world. Only a few countries, including the USA, Canada, China, and Argentina, can commercially produce shale gas. At the end of 2015, the daily shale gas output in the USA, Canada, China, and Argentina had reached 37, 4.1, 0.5, and $0.07 \mathrm{Bcf}$, respectively [100, 101]. Shale gas production in the USA abruptly increased after 2000, while Canada and China successfully produced shale gas for the first time in 2008 and 2012, respectively. There are now more than 100,000 shale gas drilling wells in the USA. In China, however, only about 600 wells have been drilled in the last few years [102]. The EGS technology is still at the research and development stage. Nevertheless, there are some experimental EGS plants and pilot projects, for example, at Fenton Hill, Coso, and Desert Peak in the USA, Bad Urach, Neustadt-Glewe, Bruchsal, Landau, and Unterhaching in Germany, and Soultz-sous-Forets and Bouillante in France [87]. Substantially higher research, development, and demonstration efforts are needed to ensure EGS technology becomes commercially viable in the near future.

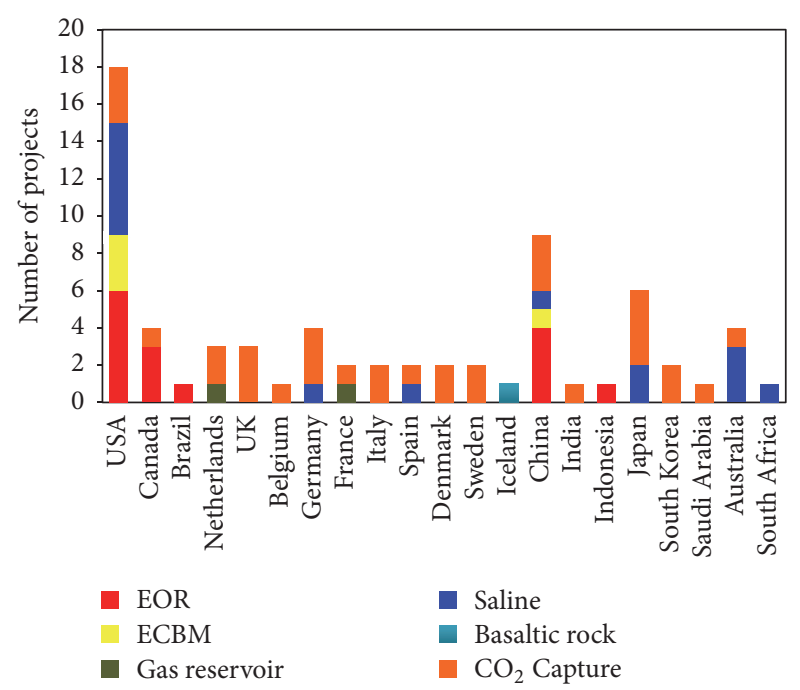

FIGURE 3: Global distribution of pilot-scale CCUS engineering projects based on project purpose and reservoir types, data sourced from http://www.globalccsinstitute.com/.

\section{Current Status of CCS and CCUS Technologies in China}

Since 2005, CCS has been listed as a frontier technology in China's mid-long term technical development program in order to realize the goal of zero emissions from fossil fuel energy [103]. Meanwhile, more attention has been paid to CCUS technology, especially $\mathrm{CO}_{2}$-EOR and $\mathrm{CO}_{2}$-ECBM [104-107]. Between 2006 and 2015, the Ministry of Science and Technology of China (MOST) funded eight National Basic Research Programs (also known as the 973 Program) and State High-Tech Development Plans (commonly known as the 863 Program). Three of these programs were related to $\mathrm{CO}_{2}$-EOR and the others to the $\mathrm{CO}_{2}$ capture technology, shale gas recovery, and the hot dry rock systems. The National Natural Science Foundation of China (NSFC) also generously funded basic research related to CCS and CCUS.

Based on the incomplete statistics of the research projects funded by MOST and NSFC during 2005-2016 (Figures 4 and 5 and Table 1), the distribution of funding for different aspects of CCS and CCUS is shown as follows: (1) CCS (32 projects), of which all the 7 projects funded by the MOST were related to $\mathrm{CO}_{2}$ capture technology. The 23 projects funded by the NSFC and 1 project funded by the Ministry of Land and Resources were concerned with $\mathrm{CO}_{2}$ storage; (2) CCUS: $\mathrm{CO}_{2}$-EOR (18 projects), of which 6 projects were funded by the MOST and 10 by the NSFC; (3) CCUS: $\mathrm{CO}_{2}-$ ECBM (22 projects), of which 3 projects were funded by the MOST, and 17 by the NSFC; (4) CCUS: $\mathrm{CO}_{2}$-EGR (4 projects); (5) CCUS: $\mathrm{CO}_{2}$-ESG (4 projects); and (6) CCUS: $\mathrm{CO}_{2}$-EGS (7 projects).

Several international cooperation research projects were also developed, including NZEC between China and Europe, CAGS between China and Australia, and CCERC between China and the USA; see Table 2 for further details. 


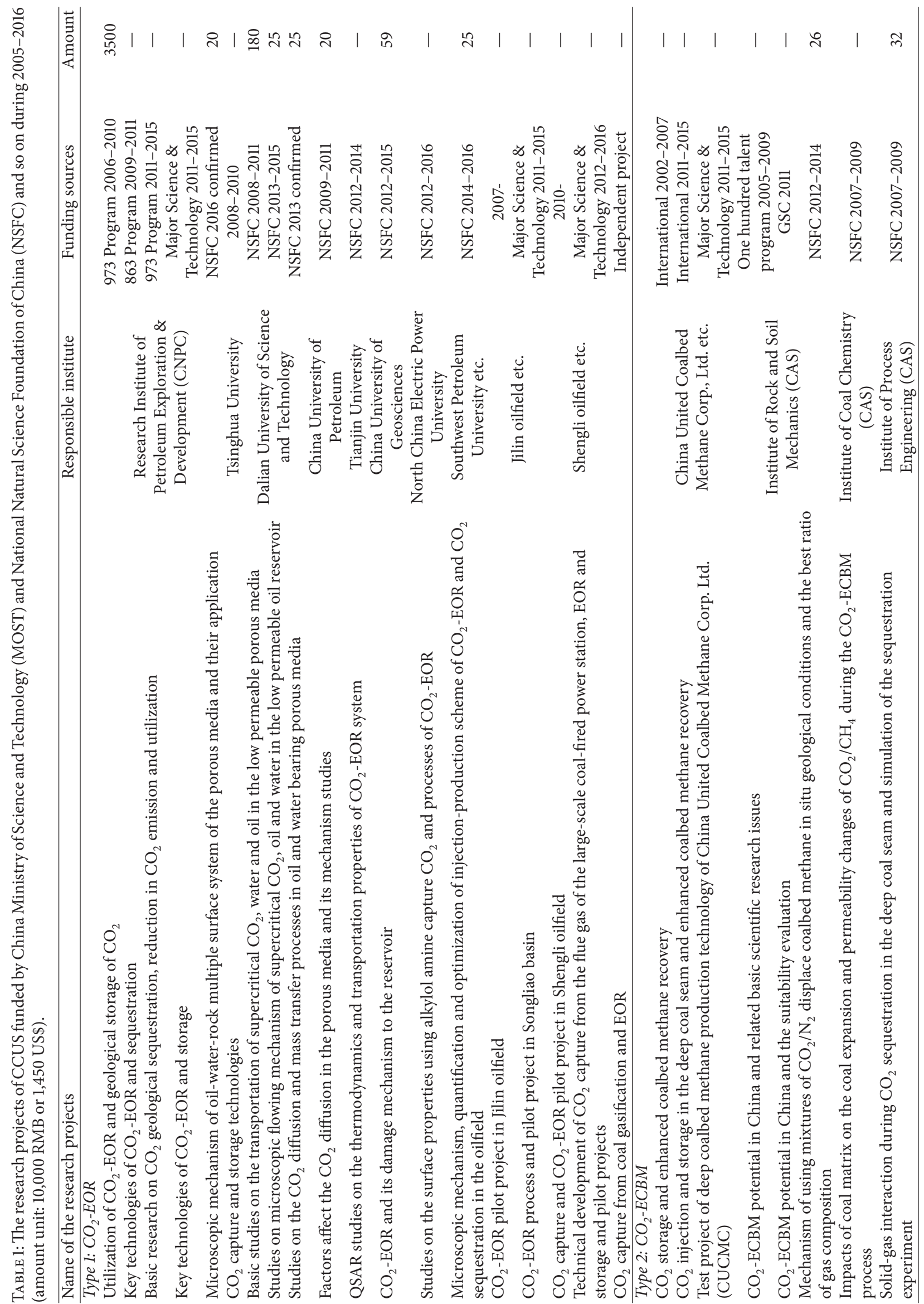




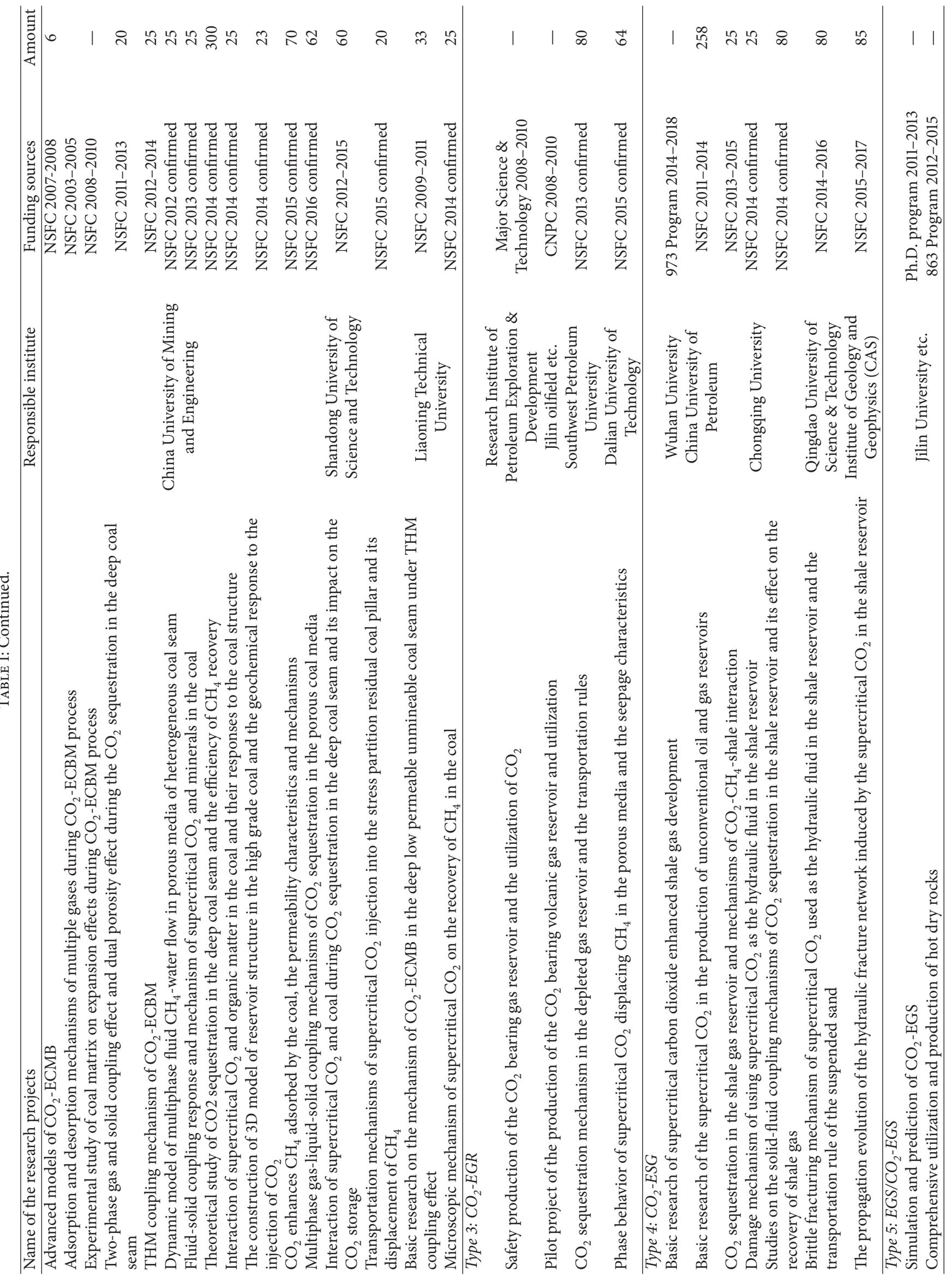




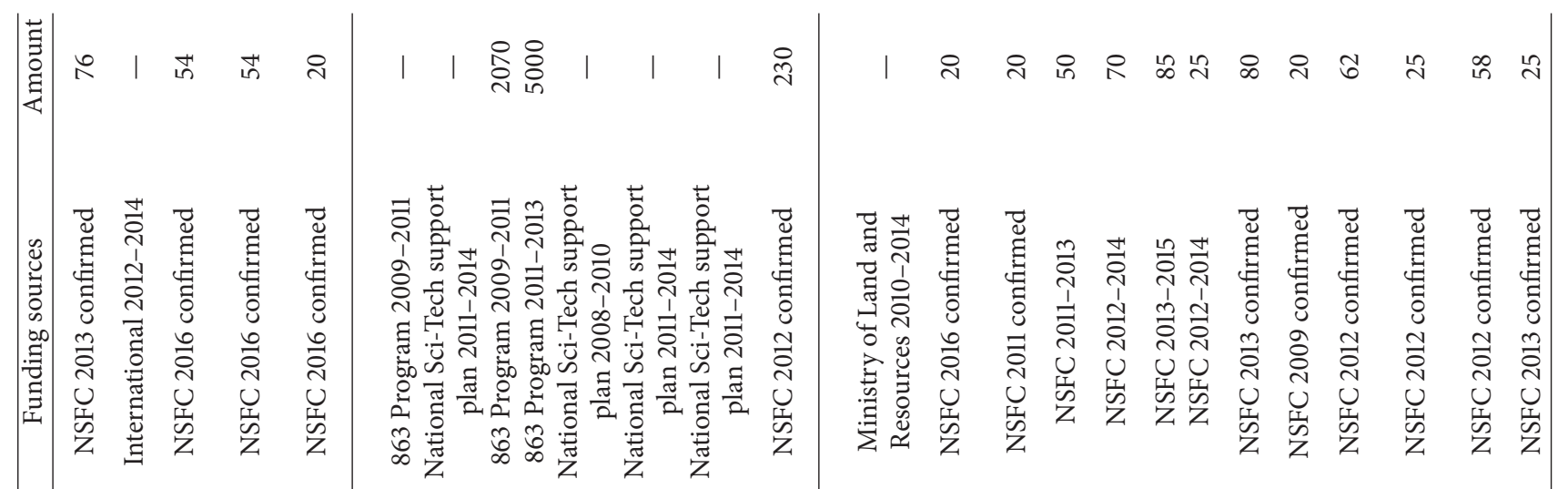

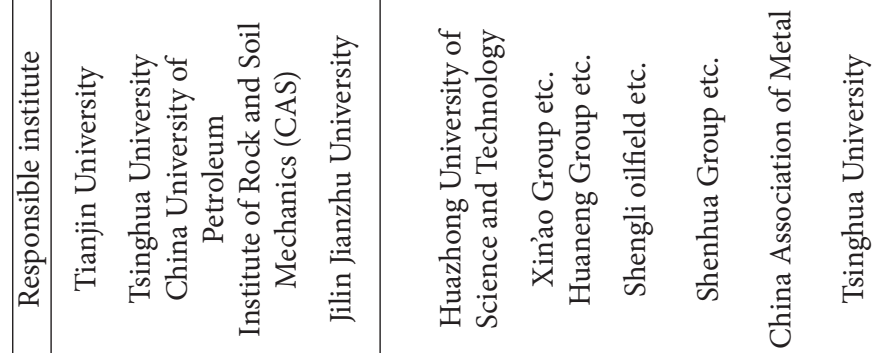

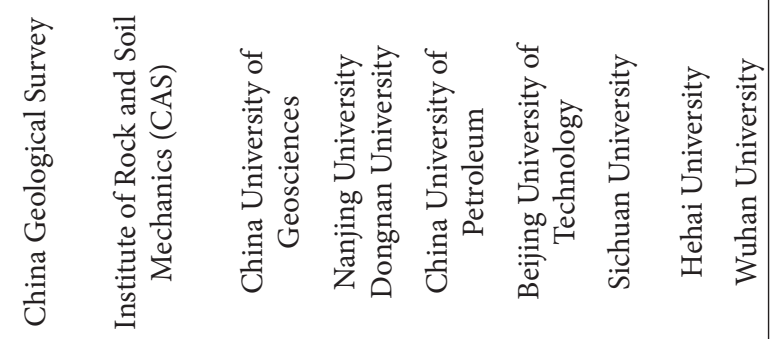

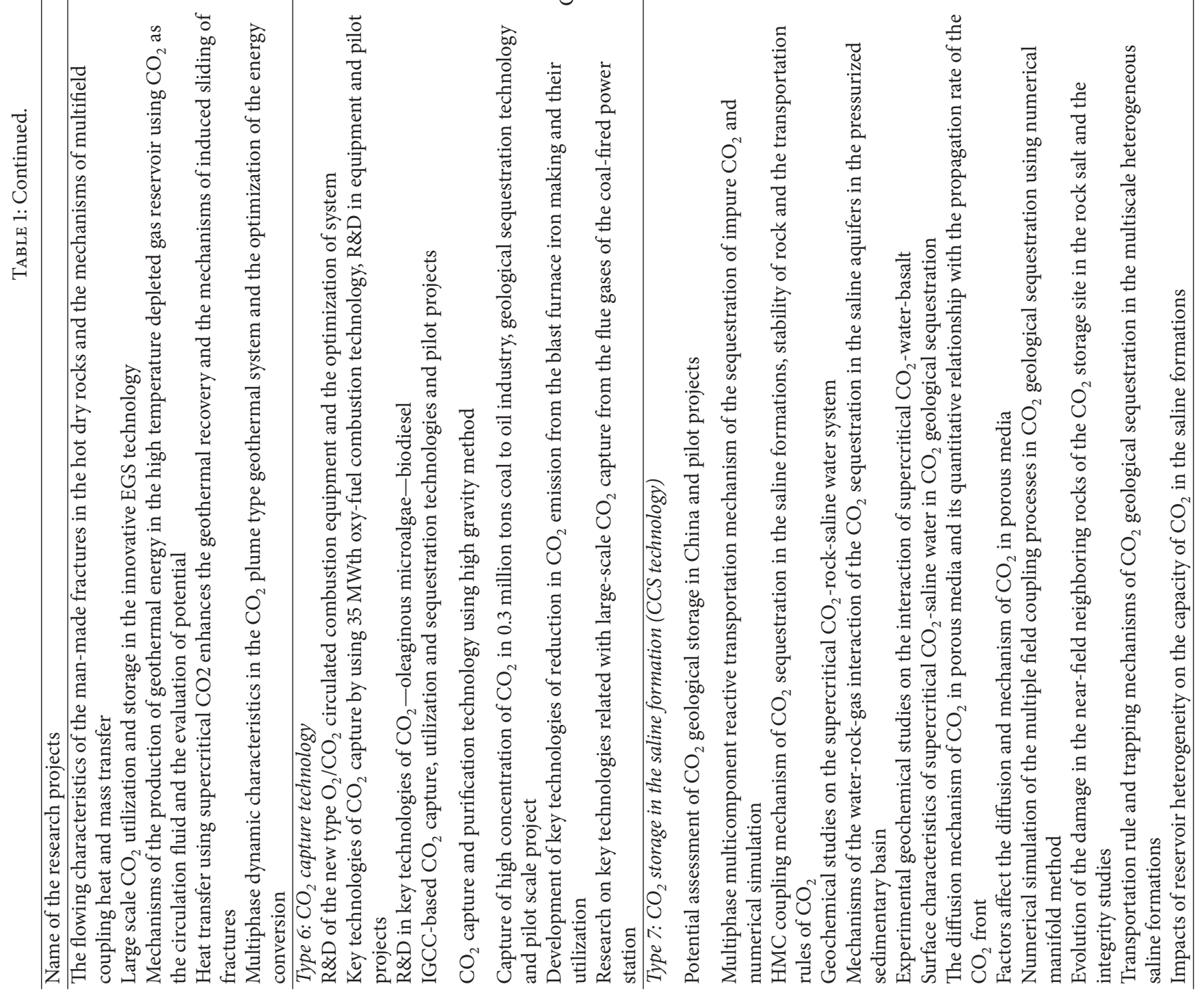




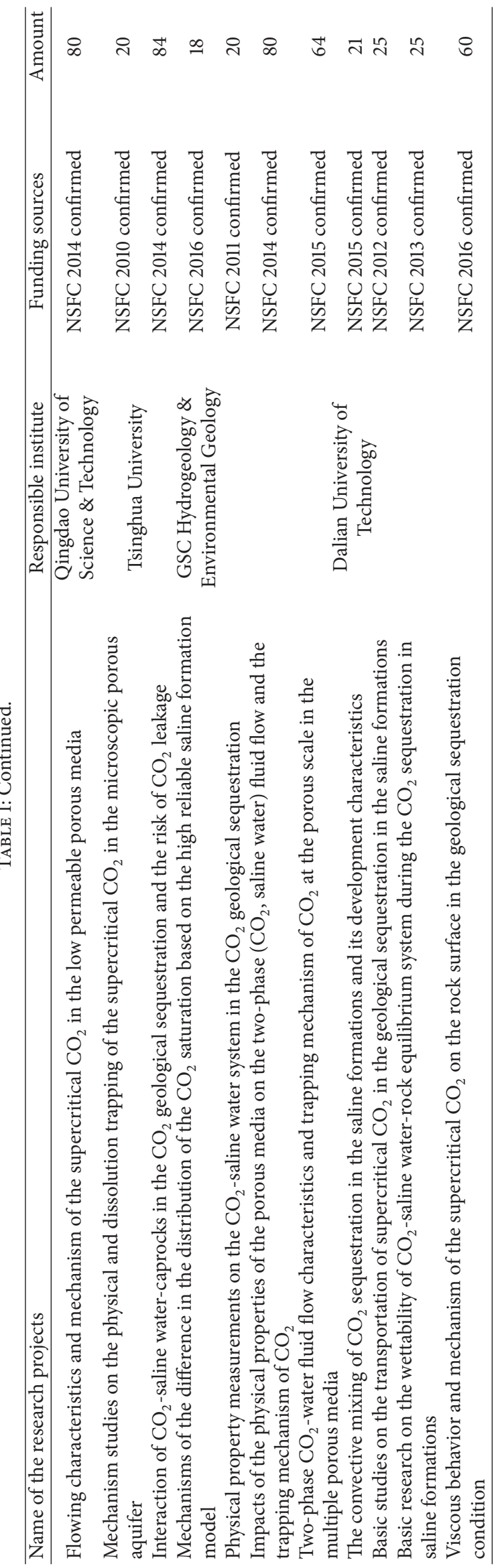


TABLE 2: China's international collaboration on CCUS projects during 2005-2016.

\begin{tabular}{|c|c|c|c|}
\hline Name of projects & $\begin{array}{l}\text { Main responsible institutes in } \\
\text { China }\end{array}$ & Funding sources & Funding \\
\hline $\begin{array}{l}\text { China-EU Cooperation on } \\
\text { Near Zero Emissions Coal } \\
\text { (NZEC) }\end{array}$ & \multirow{3}{*}{$\begin{array}{c}\text { The Administrative Center for } \\
\text { China's Agenda } 21 \text { (ACCA21) } \\
\text { etc. }\end{array}$} & $\begin{array}{l}\text { MOST, EU, UK Environment, } \\
\text { Food and Rural Affairs } \\
\text { (DEFRA) 2007-2009 }\end{array}$ & 4.5 million US\$ \\
\hline $\begin{array}{l}\text { China-Australia Geological } \\
\text { Storage of } \mathrm{CO}_{2} \text { (CAGS) }\end{array}$ & & $\begin{array}{l}\text { MOST, Australian } \\
\text { Department of Resources, } \\
\text { Energy and Tourism } \\
\text { 2010-2018 }\end{array}$ & $>4.0$ million US\$ \\
\hline China-Italy CCS project & & $\begin{array}{l}\text { MOST, Italian Ministry of } \\
\text { Environment 2010-2012 }\end{array}$ & - \\
\hline $\begin{array}{l}\text { China-Netherlands } \\
\mathrm{CO}_{2} \text {-ECBM and } \mathrm{CO}_{2} \text { saline } \\
\text { aquifer storage exchange } \\
\text { center }\end{array}$ & $\begin{array}{l}\text { Institute of Coal Chemistry } \\
\text { (CAS) etc. }\end{array}$ & $\begin{array}{l}\text { Ministry of Economic Affairs } \\
\text { 2008- }\end{array}$ & - \\
\hline $\begin{array}{l}\text { China-U.S. low emission } \\
\text { technology of IGCC }\end{array}$ & $\begin{array}{l}\text { Institute of Engineering } \\
\text { Thermophysics (CAS) etc. }\end{array}$ & $\begin{array}{l}\text { MOST, U.S. DOE } \\
\text { 2010-2012 }\end{array}$ & - \\
\hline $\begin{array}{l}\text { China-U.S. Clean Energy } \\
\text { Research Center (CCERC) }\end{array}$ & $\begin{array}{l}\text { Huazhong University of } \\
\text { Science and Technology }\end{array}$ & $\begin{array}{l}\text { MOST, U.S. DOE } \\
2010-2015\end{array}$ & 2 million US\$/year \\
\hline $\begin{array}{l}\text { China-Germany CCUS } \\
\text { project }\end{array}$ & Sichuan University etc. & $\begin{array}{l}\text { NSFC, DFZ } \\
2010-\text { now }\end{array}$ & - \\
\hline
\end{tabular}

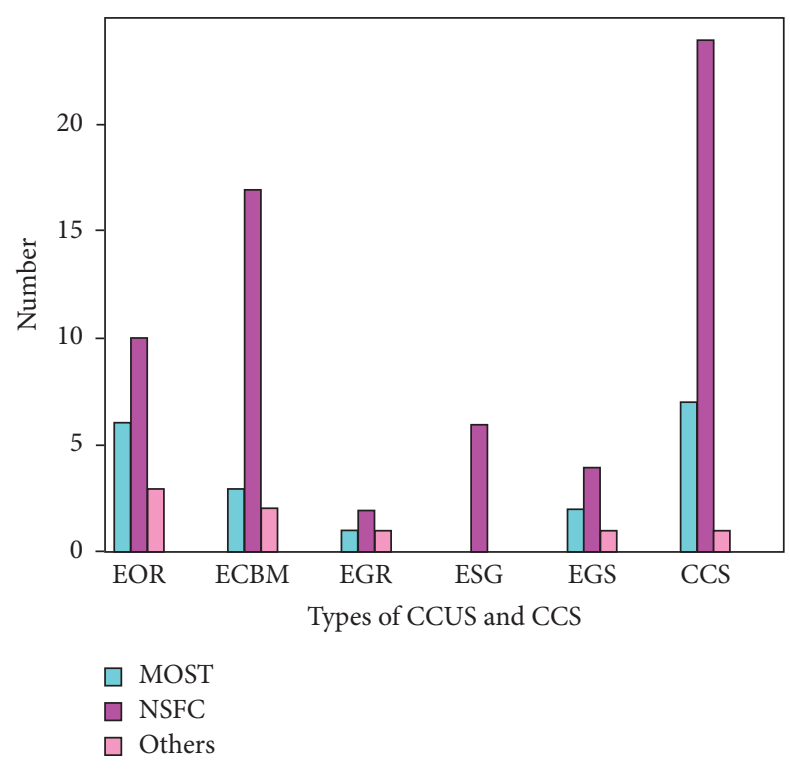

FIGURE 4: Research projects of CCS and CCUS in China during 2005-2016 based on Table 1 .

4.1. CCS. China's Geological Survey compiled a series of atlases relating to the storage capacity and suitability evaluation of China and its main sedimentary basins [25, 108112]. Combined with a selection indicator evaluation system for potential storage sites, the standardization of the CCS in China has a good foundation $[20,21,113,114]$. A preliminary evaluation of the $\mathrm{CO}_{2}$ storage potential in the saline formations at a depth of $1-3 \mathrm{~km}$ showed a capacity of $1.435 \times 10^{11}$ tonnes, and most parts of the Huabei plain and Sichuan Basin can be regarded as favorable storage sites $[115,116]$. Based on

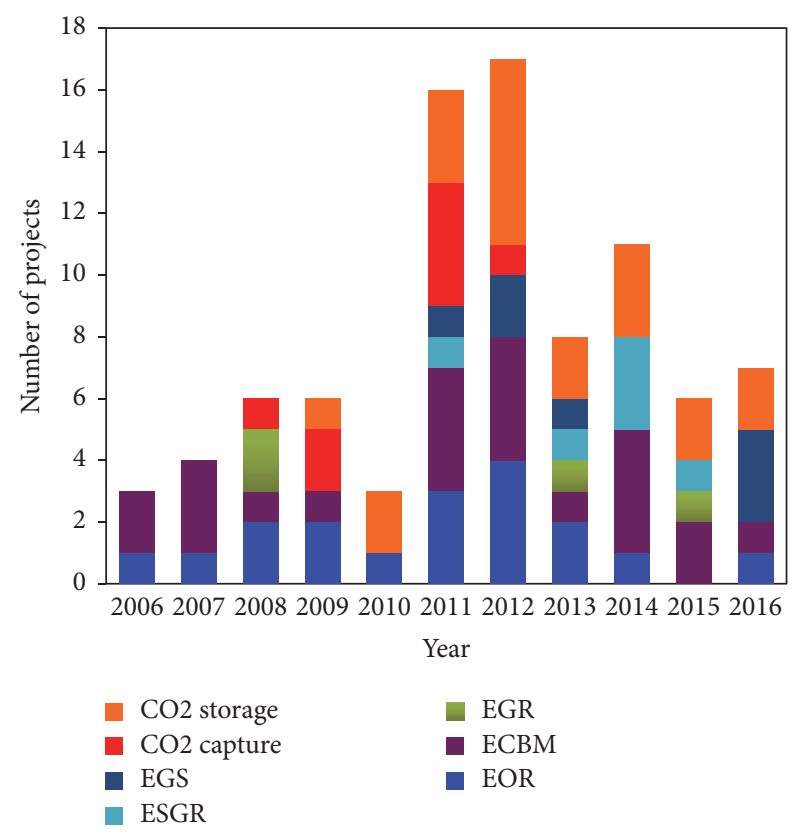

FIGURE 5: Different types of CCUS research projects in China during 2006-2016 based on Table 1.

the studies on $\mathrm{CO}_{2}$ sequestration in saline formations [117124], the first full chain CCS project in China was successfully launched in the Ordos Basin with a storage target of 0.1 million tons of $\mathrm{CO}_{2}$ injected in 2010 [125-130].

4.2. CCUS: $\mathrm{CO}_{2}-E O R$ in China. The theoretical $\mathrm{CO}_{2}$ storage capacity of depleted onshore oil reservoirs is estimated to be 3.78 gigatons of $\mathrm{CO}_{2}$ [131]. Conservative estimates reveal that 


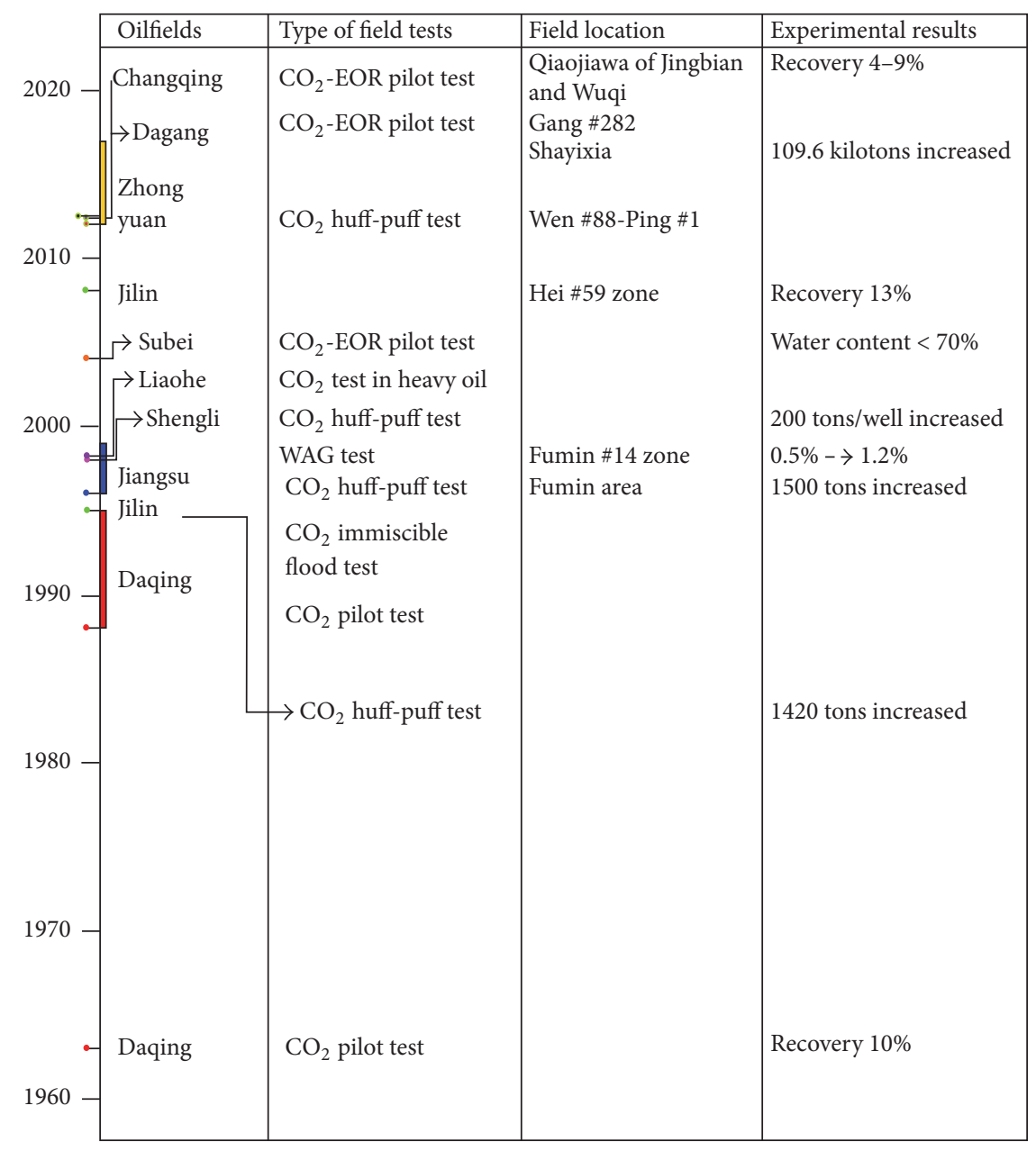

Figure 6: Development of $\mathrm{CO}_{2}$-EOR pilot tests in several oilfields in China since the 1960s.

about $70 \%$ of the oil production comes from nine oilfields, that is, Changqing, Tarim, Daqing, Shengli, Yanchang, Bohai, Liaohe, Zhongyuan, and Jilin. However, most of them are facing or will soon be depleted after many years' production. Under these circumstances, $\mathrm{CO}_{2}$-EOR technology may become an effective option to produce more oil from the depleting reservoir. In fact, China started the development of $\mathrm{CO}_{2}$-EOR technology in the 1960s in several districts of the Daqing oilfield including Ta \#112, Fang \#48, and Shu $\# 16$ and \#101 [132]. Several $\mathrm{CO}_{2}$-EOR field tests have also been carried out in other fields including Jilin, Dagang, Shengli, and Liaohe (see Figure 6), with recovery increasing to about $10 \%$ [118, 121, 132-137]. Compared with the status of $\mathrm{CO}_{2}$-EOR technology in the US, extensive application of $\mathrm{CO}_{2}$-EOR in most oilfields of China may be difficult as the geologic structure of most reservoirs is characterized by many faults and low permeability [138]. Besides, a lack of policy and regulatory incentives, high commercial uncertainty, and technical challenges affect the rapid development of the $\mathrm{CO}_{2}$ EOR technology in China.

4.3. CCUS: $\mathrm{CO}_{2}-E C B M$ in China. While studies on $\mathrm{CO}_{2}-$ ECBM technology first started in the 1990s, China began its basic research in this field (including adsorption, desorption and swelling mechanisms in the coal matrix, and the twophase gas flow of $\mathrm{CO}_{2}$ and $\mathrm{CH}_{4}$ in different types of coal rocks) at the end of 20th century [139-145]. This research was further extended to include the $\mathrm{CH}_{4}$ displacement mechanisms by using a mixture of $\mathrm{CO}_{2}$ and $\mathrm{N}_{2}$ [41, 146-151]. Based on the well test data for coalbed methane production in China, the recovery is in the range of $8.9 \%-74.5 \%$, with an average value of $35 \%$. By using $\mathrm{CO}_{2}$-ECBM technology, the recovery can be increased to 59\% [152]. Based on the preliminary evaluation of [153], the recoverable coalbed methane can increase to $1.632 \times 10^{12} \mathrm{~m}^{3}$ with $\mathrm{CO}_{2}$ storage amount of about $120.78 \times 10^{8}$ tonnes for the coalbed at a depth ranging from 300 to $1500 \mathrm{~m}$.

4.4. CCUS: $\mathrm{CO}_{2}$-EGR in China. According to the results from the third oil and gas reserve investigation, if $75 \%$ of the porous volume derived from gas production is used for $\mathrm{CO}_{2}$ sequestration, there will be a potential for a $\mathrm{CO}_{2}$ storage capacity of 5.18 billion-tons $[9,154]$. However, the gas industry in China started late and gas production is low, which means that there will not be many depleted gas reservoirs in the 
short term, limiting the possibility of a commercial scale application of the $\mathrm{CO}_{2}$-EGR technology. From the maturity point of view of this technology, very few research institutes in China are working on the improvement of $\mathrm{CO}_{2}$-EGR at the present. Furthermore, the early breakthrough of $\mathrm{CO}_{2}$ in gas production wells makes it difficult to attain good production efficiency from the application of $\mathrm{CO}_{2}$-EGR technology [47]. A means of reducing the costs of separating the mixed gases, $\mathrm{CO}_{2}$ and $\mathrm{CH}_{4}$, is required to attain the widespread application of the $\mathrm{CO}_{2}$-EGR technology in China.

4.5. CCUS: $\mathrm{CO}_{2}-E S G$ in China. Encouraged by the successful exploitation of shale gas in North America, China joined the exploration of shale gas in 2005 [155]. The published data from the Ministry of Land and Resources in 2002 confirms that China had a shale gas reserve of $25.1 \times 10^{12} \mathrm{~m}^{3}$. By the end of 2015, China had a technical shale gas reserve of about $1.3 \times 10^{11} \mathrm{~m}^{3}$ including the increased proved technical reserve of $1.09 \times 10^{11} \mathrm{~m}^{3}$.

In December 2010, China drilled its first shale gas exploration well, Wei201 in Weiyuan gas field [155]. In May 2012, the first shale gas horizontal well in China was drilled and operated by Yangchang oilfield, demonstrating a great breakthrough in the hydraulic fracturing technology for shale gas reservoirs. By the end of 2012, China's total shale gas production was $2.5 \times 10^{7} \mathrm{~m}^{3}$, which increased to $2.0 \times 10^{8} \mathrm{~m}^{3}$ in 2013, $1.3 \times 10^{9} \mathrm{~m}^{3}$ in 2014, and $4.47 \times 10^{9} \mathrm{~m}^{3}$ in 2015 . The production of shale gas in China has increased greatly during the last few years, especially from the Peiling shale gas field in Chongqing with a proved reserve of more than $1.0 \times 10^{11} \mathrm{~m}^{3}$. It has produced shale gas of about $1.03 \times$ $10^{9} \mathrm{~m}^{3}$, becoming the largest commercial shale gas field in China.

However, high production costs, a large amount of water consumption and a breakthrough in some key technologies related to shale gas production will restrict large-scale production in the near future [102]. In 2012, the National Energy Administration of China set a target for shale gas production of $6 \times 10^{10}-1.0 \times 10^{11} \mathrm{~m}^{3}$ by 2020 . But after a two years' practical experience during 2012-2013, it revised this target to $3.0 \times 10^{10} \mathrm{~m}^{3}$ by 2020 . Using $\mathrm{CO}_{2}$ to enhance the recovery of shale gas is now at an early exploration stage [156].

4.6. CCUS: $\mathrm{CO}_{2}$-EGS in China. The 863 plan project that aims at investigating EGS was initiated by Jilin University in 2012 [157]. There are now several other projects in the country using $\mathrm{CO}_{2}$ in geothermal production (see Table 1). This demonstrates that China is interested in developing EGS to exploit the deep geothermal resources from the hot dry rocks. Many Chinese researchers (e.g., [143, 158-162]) have already studied the operation mechanisms of the $\mathrm{CO}_{2}$ EGS system and its optimization designs. A preliminary site selection system considering the role of $\mathrm{CO}_{2}$ in the geothermal production was set up by [26]. Research in this technology is still at the very early stage and requires detailed work to attain pilot scheme status.

\section{Status of CCUS Engineering Projects in China}

The $\mathrm{CO}_{2}$ emission sources are mainly located in the middleeastern regions of China; see details in Figure 2.15, [34]. Therefore, pilot-scale CCUS (mostly $\mathrm{CO}_{2}$-EOR) engineering projects in China are also located in these regions (Figure 7 , Table 3). Based on published government and industrial reports and personal communications, the progress of pilotscale CCUS engineering projects in China is as follows:

(1) $\mathrm{A} \mathrm{CO}_{2}$-EOR field test was executed for the first time in Daqing oilfield in 2003. In recent years, the industrial injection of $\mathrm{CO}_{2}$ and the production of oil with the help of $\mathrm{CO}_{2}$-EOR technology operated by the Daqing oilfield are mainly located in the Yushulin and Hailaer oilfields.

(2) $\mathrm{A} \mathrm{CO}_{2}$-EOR project with a $\mathrm{CO}_{2}$ injection amount of $0.8-1$ million tons/year in Jilin oilfield (still in operation) since 2005 for the exploitation of the $\mathrm{CO}_{2}$ rich (21\% $\mathrm{CO}_{2}$ concentration) Changling gas field. A $\mathrm{CO}_{2}$-EOR experiment has been carried out by Jilin oilfield in 2006 and oil recovery enhanced by $8 \%-10 \%$. The Changling gas field was the first project to integrate natural gas production, $\mathrm{CO}_{2}$ sequestration, and EOR technology [7]. As the conventional water injection method does not provide good production efficiency in low permeable oilfields, $\mathrm{CO}_{2}$-EOR has played a large role in increasing production, such as in the Fuyang oilfield [137]. By March 2017, oil production increased to 100 kilotons by injecting 1.1 million tons of $\mathrm{CO}_{2}$ underground.

(3) A full chain pilot-scale $\mathrm{CO}_{2}$-EOR project has been injecting $\mathrm{CO}_{2}$ at a rate of 40,000 tons/year in the Shengli oilfield (still in operation). The Sinopec Shengli oilfield cooperated with the Shengli power plant to install the largest equipment for capturing exhaust gases in a coal power plant [163]. Its purpose is to reduce $\mathrm{CO}_{2}$ emission by 30 kilotons/year and enhance oil recovery by $20.5 \%$. This project started in 2008 and about 251 kilotons of $\mathrm{CO}_{2}$ had already been injected in the ultralow permeable oil reservoir through 11 injection wells by April 2015.

(4) $\mathrm{A} \mathrm{CO}_{2}$-EOR project operated by Zhongyuan oilfield (still in operation) injected $\mathrm{CO}_{2}$ at a rate of 30,000 tons/year and managed to increase oil production by 3600 tons after injection of 2170 kilotons of $\mathrm{CO}_{2}$ and 827 kilotons of water [7]. By February 2017, a total amount of about 553 kilotons of $\mathrm{CO}_{2}$ was injected underground. As a result, oil recovery is proved to have enhanced by $10 \%$ in the Zhongyuan oilfield and by $60 \%$ in the Shayixia oilfield after the pilot-scale test.

(5) The $\mathrm{CO}_{2}$-EOR project led by the Yangchang oilfield company was carried out in 2013 using captured $\mathrm{CO}_{2}$ during the production of methanol and acetic acid. At present, the capture equipment designed for 360 kilotons/year of $\mathrm{CO}_{2}$ is under construction. Pilotscale $\mathrm{CO}_{2}$-EOR field tests have been done in some 


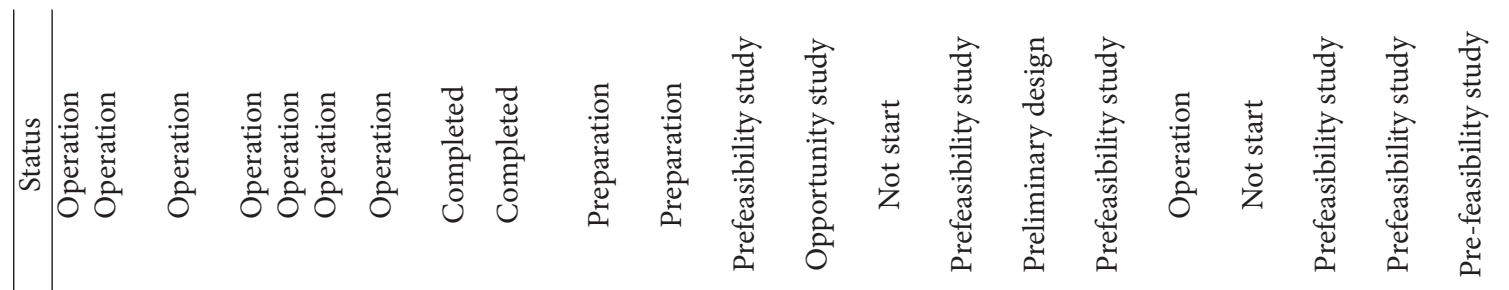

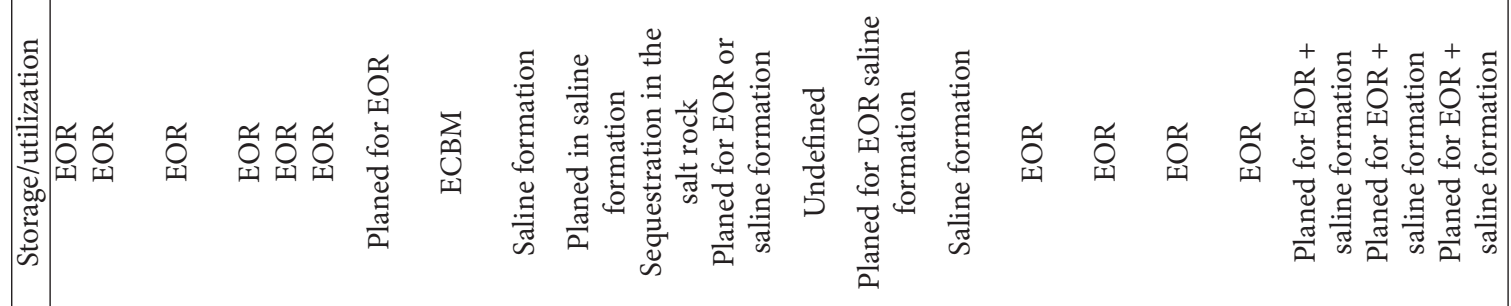

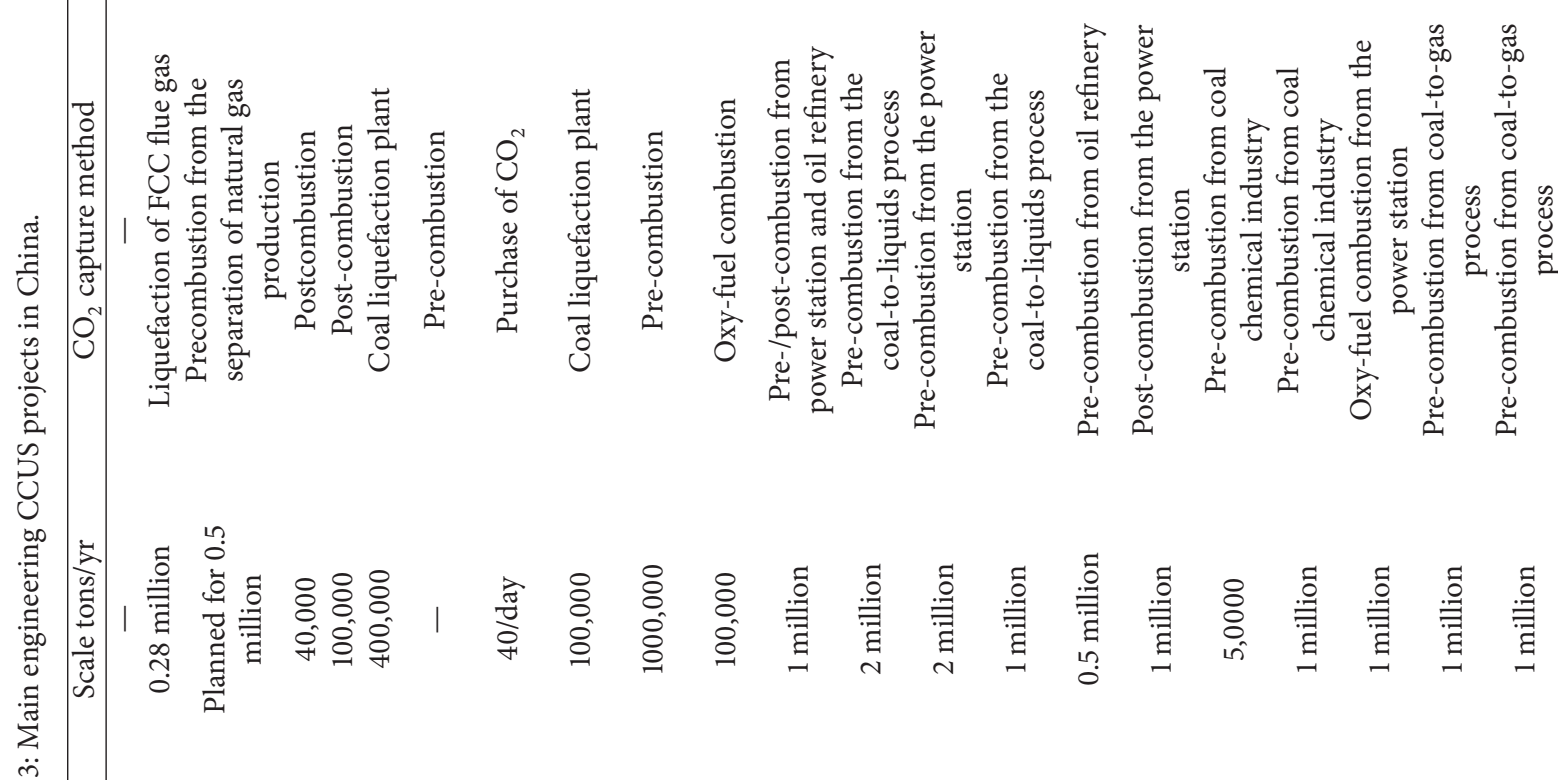

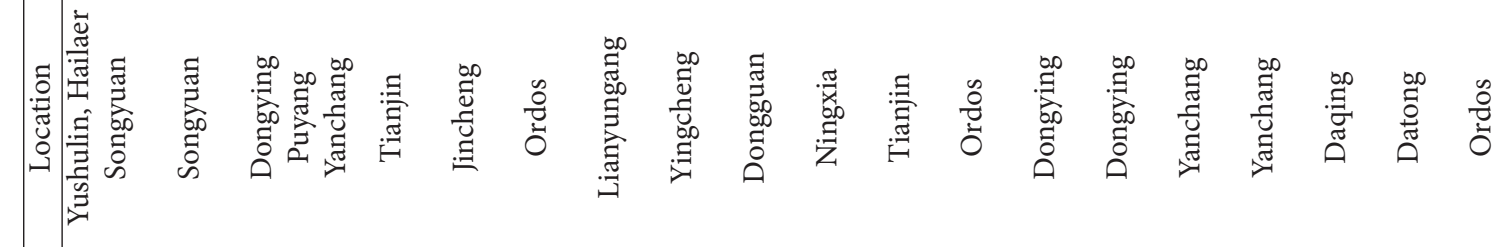

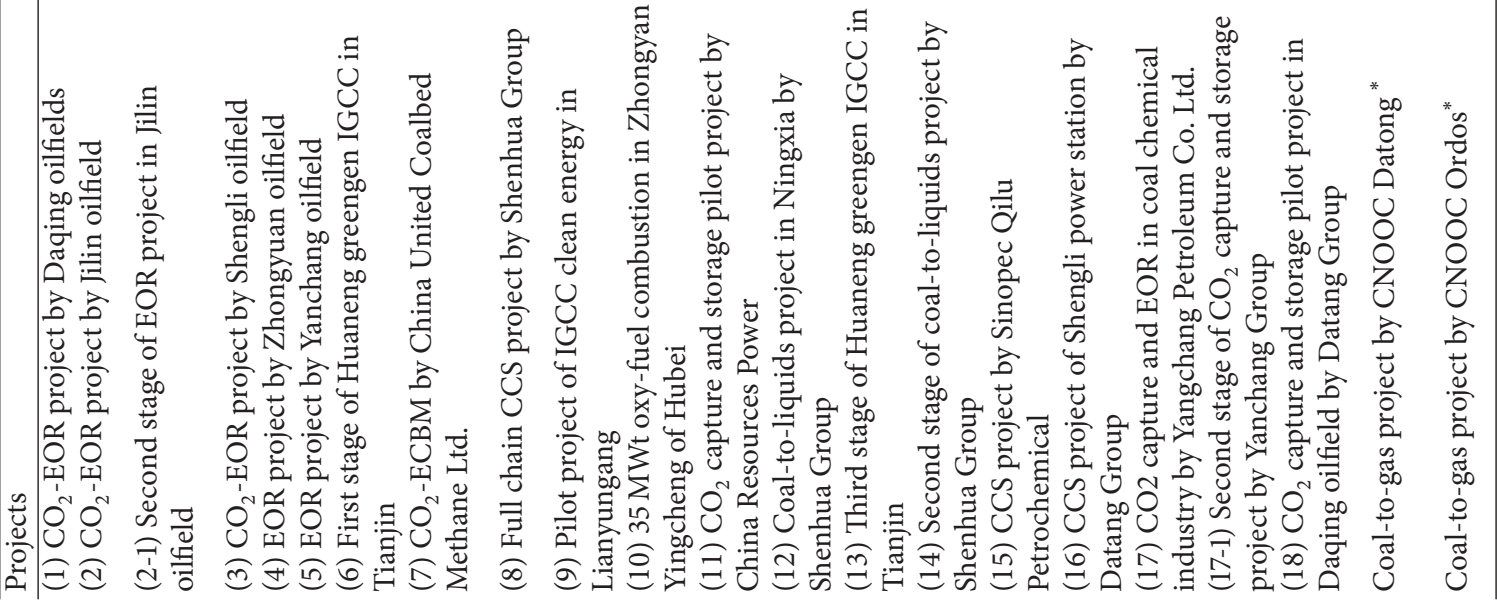




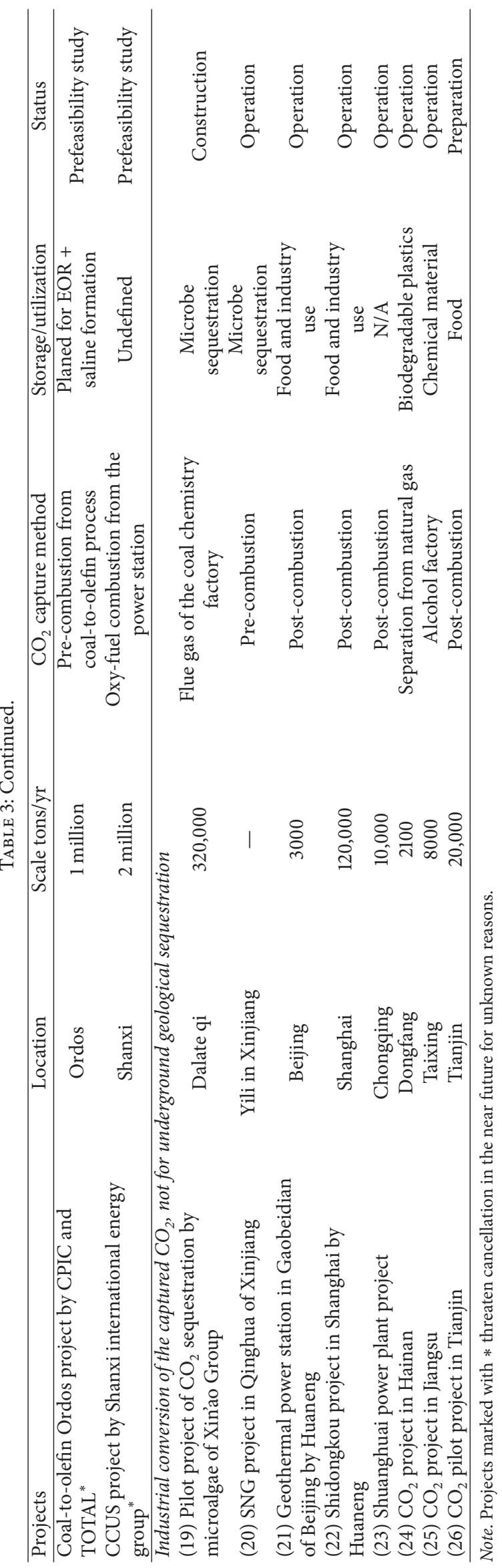




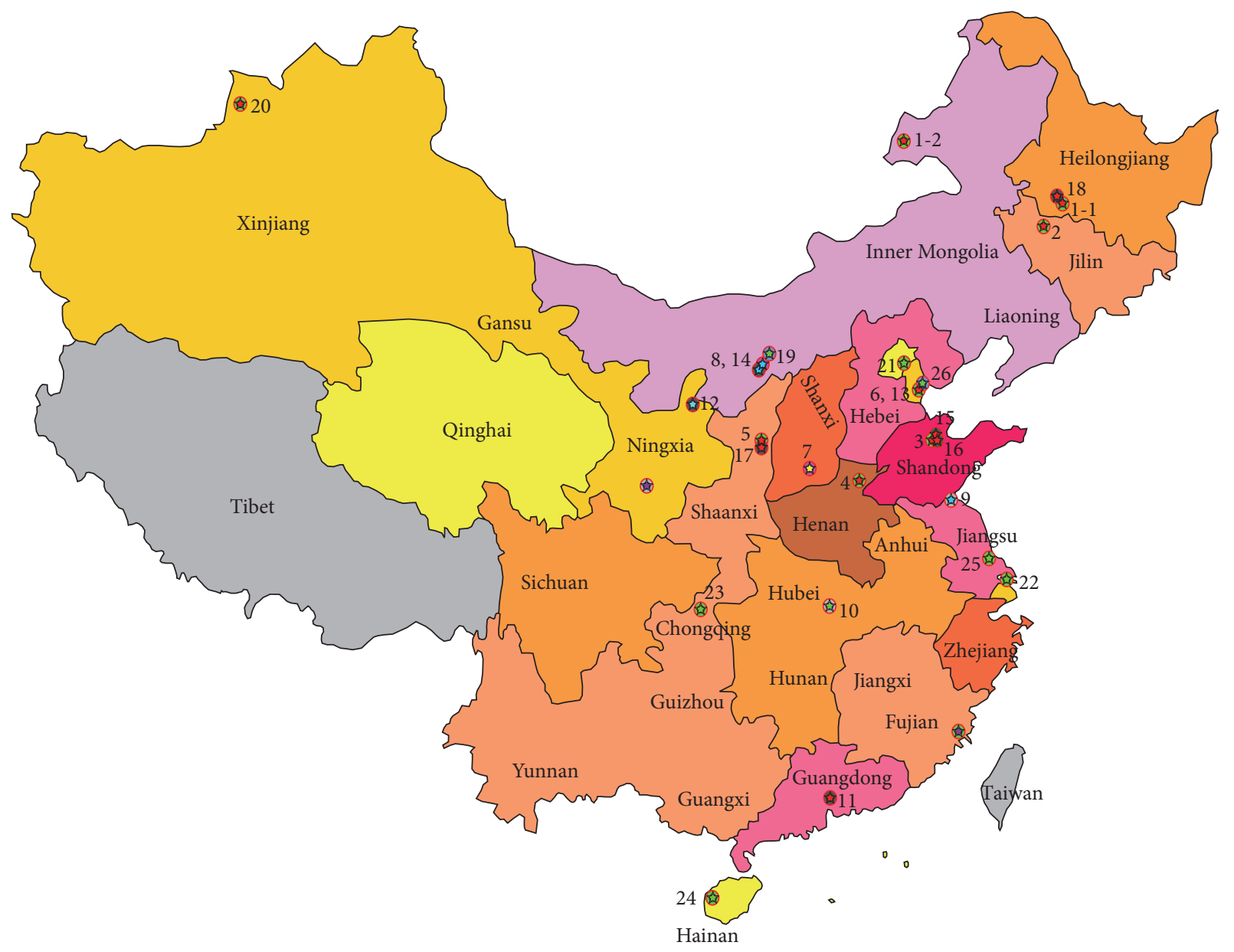

\begin{tabular}{|c|c|c|c|}
\hline & & unit: million to & \\
\hline $\mathrm{CO}_{2}$-EOR & Completed & $\square$ no data & $\square 300-400$ \\
\hline $\mathrm{CO}_{2}-\mathrm{ECBM}$ & Operation & $\square 0-50$ & $\square 400-500$ \\
\hline $\mathrm{CO}_{2}$ in saline & Construction & $\square$ 50-100 & $\square$ 500-600 \\
\hline $\mathrm{CCU}$ & Preparation & $\square 100-200$ & $\square 600-700$ \\
\hline EGS & Evaluation & $\square$ 200-300 & $700-800$ \\
\hline
\end{tabular}

FIgURE 7: Distribution of CCUS engineering projects in China excluding the South China Sea Islands (numbers defined in Table 3) superimposed on the provincial $\mathrm{CO}_{2}$ emission map for the year 2010 (from [34]).

districts of Jinbian and Wuqi, with a total of 90 kilotons $\mathrm{CO}_{2}$ injected.

(6) As the first demonstration of IGCC power station in China, the first stage of the IGCC project at Tianjin combined with the $\mathrm{CO}_{2}$ capture and EOR technology, with an installation capacity of $265 \mathrm{MW}$, has been in operation since November 2016.

(7) The $\mathrm{CO}_{2}$-ECBM project located in the Qinshui basin of Shanxi Province operated by China United Coalbed Methane Corporation, Ltd (completed) [7, 164]. It is the only pilot-scale $\mathrm{CO}_{2}$-ECBM field test in China and operates at an injection rate of 40 tonnes/day of $\mathrm{CO}_{2}$. This is a cooperation project between the Zhonglian coalbed methane Ltd and
Canada which aims at studying the feasibility of $\mathrm{CO}_{2}-$ ECBM in China [53].

(8) The full chain CCS project in the saline formations located in the Ordos of the Inner Mongolia (completed). This is the first full chain CCS project in China, with a capital investment of more than 28.6 million US\$. The drilling of one injection (with a completion depth of $2826 \mathrm{~m}$ ) and two monitoring wells (31 and $70 \mathrm{~m}$ away from the injection well) started in 2010. Since September 2011 until 2015, a total amount of 300,000 tons $\mathrm{CO}_{2}$, produced by the coal liquefaction factory of the Shenhua Group, has been transported by oil tankers and injected in four saline formations and one carbonate formation [165]. The first stage of injection test started in 2011, with 
the wellhead injection pressure ranging from 6.79 to $8.63 \mathrm{MPa}$. The second production test started in 2012 with varying injection rates of $6 \mathrm{~m}^{3} / \mathrm{h}, 9 \mathrm{~m}^{3} / \mathrm{h}$, $12 \mathrm{~m}^{3} / \mathrm{h}$, and $15 \mathrm{~m}^{3} / \mathrm{h}$ and constant wellhead injection pressure of $5.7 \mathrm{MPa}$ and temperature of $5^{\circ} \mathrm{C}$. Another large-scale $\mathrm{CO}_{2}$ sequestration in the deep saline formations located in Lianyungang of Jiangsu Province is in preparation.

(9) $\mathrm{A} \mathrm{CO}_{2}$ storage project in the rock salt at Yingcheng in Hubei Province, where $\mathrm{CO}_{2}$ will be captured by the oxy-fuel combustion technology, is in preparation [166].

(10) $\mathrm{CO}_{2}$ sequestration by microbe algae has also been identified an effective means to reduce $\mathrm{CO}_{2}$ concentration in the atmosphere. The two representative $\mathrm{CO}_{2}$ sequestration projects using microbe algae are the Xin'ao and Qinghua groups both from China.

In the next few years, $\mathrm{CO}_{2}$-EOR engineering projects will still be the most important CCUS technology in application. After the successful experience attained from the pilot-scale CCUS projects so far, China is now planning to run 13 large-scale CCUS projects. Based on the stages of the engineering projects, the project will be divided into the following study phases: opportunity $\rightarrow$ preliminary $\rightarrow$ prefeasibility $\rightarrow$ feasibility $\rightarrow$ construction drawing design $\rightarrow$ construction $\rightarrow$ operation $\rightarrow$ completed. All the stages before the construction drawing design phase, that is, preparation of the engineering projects, could be lumped together and called the "evaluation" stage. Due to the current low oil price and a lack of the motivation policy, the progress in developing most of these large-scale planning CCUS projects lags far behind the schedule. Most of these projects are still at prefeasibility or feasibility stages and some may even be cancelled.

Although capturing and industrial utilization of $\mathrm{CO}_{2}$ in China are not the key aims of this paper, the related projects in operation include (1) Huaneng Beijing thermal power plant; (2) Huaneng Shanghai Shidongkou; (3) China Power Investment Corporation Chongqing Shuanghuai; (4) $\mathrm{CO}_{2}$ project in Hainan operated by China National Offshore Oil Corporation (CNOOC); (5) $\mathrm{CO}_{2}$ project in Jiangsu province operated by the Zhongke $\mathrm{CO}_{2}$ Jinlong company. The $\mathrm{CO}_{2}$ pilot-scale project in Tianjin organized by China Guodian Power is in preparation.

At present, China does not execute any $\mathrm{CO}_{2}$-EGS field tests. However, a few engineering EGS projects exist at their early scientific field test stages. These include (1) the hot dry rock scientific drilling project in Zhangzhou Fujian province, in operation since May of 2015, with a drilling depth of $4000 \mathrm{~m}$ and a water temperature high enough for geothermal power generation and (2) a hot dry rock scientific drilling project in Qinghai Province, with a water temperature of $200^{\circ} \mathrm{C}$ at a depth of $3000 \mathrm{~m}$ [157]. Studies on power generation in traditional hydrothermal fields located in Yangyi, Xizang, and Tengchong in Yunnan Province are also undergoing. However, there are no active engineering projects related to $\mathrm{CO}_{2}$-EGR and $\mathrm{CO}_{2}$-ESG in China.

\section{Challenges in the Widespread Application of CCUS in China}

6.1. Tackling Problems in Key Technologies. The injection of $\mathrm{CO}_{2}$ underground for the CCS and CCUS purposes involves multiple physical-chemical coupling interactions of multiple components in porous fractured media, especially the transmission and migration of fluids between porous media with a low/ultralow permeability and complex fractured network.

(a) There are mature commercial $\mathrm{CO}_{2}$-EOR technologies in the USA and Canada. In China, however, because of the strong heterogeneity in oil reservoirs, the $\mathrm{CO}_{2}$ channeling effect is serious [138]. Therefore, improving the sweep efficiency is the key to attaining widespread application of $\mathrm{CO}_{2}$-EOR in China. Other efficient methods include the alternating injection of water and $\mathrm{CO}_{2}$ (WAG) and the addition of foaming and gelling agent [132].

(b) There are currently no commercial scale $\mathrm{CO}_{2}$-ECBM engineering projects being developed anywhere in the world. In China, studies on $\mathrm{CO}_{2}$-ECBM technology are at a very early stage of exploration. More research is required to tackle key problems like the adsorptiondesorption process between $\mathrm{CH}_{4}$ and $\mathrm{CO}_{2}$ in the coal seam $[46,146,147]$, the mechanisms of the interaction between $\mathrm{CO}_{2}-\mathrm{CH}_{4}-\mathrm{H}_{2} \mathrm{O}$ at molecular scale [150], the impact of the coal grade, water content and composition of coal, and so on on the diffusion and migration of mixed gases in the coal seam, the dynamic changes of phase behaviour during the process of $\mathrm{CO}_{2}$ injection, and $\mathrm{CH}_{4}$ production and so on.

(c) In the application of the $\mathrm{CO}_{2}$-EGR technology, more effort is required to prevent the early breakthrough of $\mathrm{CO}_{2}$ into the production well, thus enhancing the sweep efficiency of $\mathrm{CO}_{2}$. Thus more studies are needed like the understanding of migration processes of the $\mathrm{CO}_{2}$ after its injection into the depleted gas reservoir, phase behaviour, the mixing mechanism of $\mathrm{CO}_{2}$ and $\mathrm{CH}_{4}$, and so on $[48,60]$.

(d) Multistage hydraulic fracturing in the horizontal wells has been widely used in shale gas production in China. However, this technology is still not mature enough for the production of shale gas at depths $>3500 \mathrm{~m}$. The large amount of water consumed in the production of shale gas is a big challenge for its large-scale production, especially in southwestern China, where the existing water resources are very poor. Using $\mathrm{CO}_{2}$ as the fracturing fluid has become a research hot spot in China [167]. Injection of $\mathrm{CO}_{2}$ to extract brine or methane energy from the aquifers was also studied recently [168]. While the feasibility of using $\mathrm{CO}_{2}$ to enhance shale gas recovery still requires more research and field tests.

(e) The direct use of geothermal energy in China has been the priority during the last few years, while its use for power generation largely lags behind that of 
several countries, such as the USA, the Philippines, Japan, and Indonesia. Technologies including $\mathrm{CO}_{2}-$ AGES, EGS, and binary cycle power plants may have a positive effect on the development of China's geothermal power system. However, before obtaining mature engineering experiences, China needs to enlarge its investment in human, physical, and financial resources in these technologies.

6.2. Negative Impacts on the Environment and Resources. The risk of leakage of the injected $\mathrm{CO}_{2}$ in the injection/production wells may have a serious environmental impact [169-173]. The groundwater quality may deteriorate if the $\mathrm{CO}_{2}$ in the injection layer leaks into the freshwater aquifer through microfractures or faults $[174,175]$. When hydraulic fracturing is applied to shale gas or geothermal energy production, it will induce microseismic events. In addition, the toxic chemical additives in the hydraulic fluid may have a serious negative impact on freshwater aquifers when they leak into the shallow layers because of possible geological hazard. Therefore, a long-term environmental monitoring activity should be carried in parallel with the CCUS engineering project to ensure its safety [104]. The dynamic migration process of $\mathrm{CO}_{2}$, chemical interaction among $\mathrm{CO}_{2}$-reservoir fluid-rock, the deformation or eruption of injection/overlying caprocks, and temperature and pressure changes in the reservoir should be monitored for a long time after the injection $[29,176]$.

6.3. Storage Capacity Data Is Not Clear. The total amount of resources and the distribution of depleted oil and gas fields, deep unmineable coal seams, deep saline formations, shale gas, and rock salt reservoirs are not clearly known because of the inadequacy of the geological data. Thus to attain a widespread application of CCUS technologies, more accurate evaluation work should be done based on geological, geophysical, geochemical, rock mechanics data, and so on.

6.4. Policy Factor. The positive effect of China's involvement in CCUS technologies in recent years has been to focus on developing $\mathrm{CO}_{2}$-EOR, the capture of $\mathrm{CO}_{2}$, the shale gas and hot rock geothermal energy production, and especially shale gas production with a subsidy of $4 \mathrm{US} \$ / \mathrm{m}^{3}$ during 2016-2018 and $3 \mathrm{US} \$ / \mathrm{m}^{3}$ during 2019-2020. However, other fields of CCUS also need to be supported by the government.

6.5. High Investment Costs. The cost of a CCS or CCUS project mainly includes $\mathrm{CO}_{2}$ capture, transportation, drilling, injection, and monitoring. Costs for the capture of $\mathrm{CO}_{2}$ produced by the technologies of precombustion, postcombustion, or oxy-fuel combustion take the largest proportion in the investment of a specific CCS or CCUS project. Taking a coal-fired power station as an example, if $80 \%$ of the $\mathrm{CO}_{2}$ emitted is captured and compressed to a certain pressure, its energy consumption will increase by $24 \%-40 \%$ [177]. In the US, the price of electricity generated from a coal-fired power station is 82-99 US\$/MWh and 83-123 US\$/MWh without and with the $\mathrm{CO}_{2}$ capture technology, respectively, [178]. Depending on different situations and technologies in US, the capture cost is $42-87 \mathrm{US} \$ /$ ton $\mathrm{CO}_{2}$, transportation costs range from 4.3 to $7.2 \mathrm{US} \$ /$ ton $\mathrm{CO}_{2} / 250 \mathrm{~km}$, while injection and storage costs are 1-12 US\$/ton $\mathrm{CO}_{2}$ based on the prices in 2013. In China, the cost of electricity generation by coalfired power station increases by $30 \%-50 \%$ using $\mathrm{CO}_{2}$ capture technology due to the extra consumption of electricity and steam. Taking the Huaneng Beijing coal-fired power station as an example, the capture price is about $24.3 \mathrm{US} \$ /$ ton $\mathrm{CO}_{2}$, with the $\mathrm{CO}_{2}$ capture efficiency of $80 \%-85 \%$ [179]. On the other hand, simulation results of the IGCC coal-fired power station with the CCS technology in Tianjin show the capture price to range from 21.3 to $24.8 \mathrm{US} \$ /$ ton $\mathrm{CO}_{2}$, accounting for $80 \%$ of the price of a full-scale CCS project $[180,181]$. However, the uncertainty in the $\mathrm{CO}_{2}$ capture price is high depending on different capture technologies including precombustion, postcombustion, and oxy-fuel combustion at various stationary point sources including coal-fired power stations, cement factories, and coal chemical industries. From the aforementioned point of view, the uncertainty in the investment of a specific CCS or CCUS engineering project is determined by the cost of $\mathrm{CO}_{2}$ capture. Therefore, a reduction in the cost of $\mathrm{CO}_{2}$ capture is the key to the widespread application of CCS or CCUS technologies. Besides, drilling costs are large for all types of CCUS engineering projects and hydrocarbon/geothermal production, taking a shale gas well as an example, it costs 5.8 million US\$ for a drilling length of 2500-3000 m, and 0.72 million US\$ for a general gas well. The drilling cost of a geothermal production well in a hot dry rock will be much higher. The corrosion property of $\mathrm{CO}_{2}$ requires a high quality of pipelines and ground equipment, increasing the production costs of oil, gas, and geothermal energy $[182,183]$.

6.6. Energy Price. The slump in the international oil price has greatly affected the investment in the oil/gas production and CCUS projects. Shale gas production in Peiling shale gas field in southwestern China with good geological conditions and large reserves is just above the breakeven point. If the oil/gas price remains low in the future, many industries will be unwilling to invest in these kinds of projects. With the exception of $\mathrm{CO}_{2}$-EOR, it is difficult to profit from other CCUS projects. Due to completion from the increased installation capacity of wind and solar energy that have been much easier to make an economic return in recent years, the development in geothermal power generation will be continuously limited because of the difficulty in returning an economic benefit.

6.7. Social Acceptance. This is the biggest challenge for any CCS or CCUS project. It has a substantial impact on political decision makers and the implementation of energy projects such as nuclear power and wind energy programs [184]. It is the same for CCS and CCUS projects, and some CCS exploration activities in Schleswig-Holstein and Vattenfall Janschwalde in Germany, the Belchatow project in Poland, and so on were postponed or cancelled because of the lack of public acceptance over the exploration of storage sites $[185,186]$. As the most unfamiliar technology to the general public in China, CCUS technology has been reluctantly accepted when compared with other low carbon technologies 
including wind power, solar power, energy efficiency, or biomass for reasons of climate change mitigation [10, 187]. However, there is now a positive attitude towards CCUS policies in China. In order to stimulate public acceptance, the uncertainties regarding safety and environmental risks involved in CCUS will have to be reduced at the beginning of the development stage of any CCUS technology [188]. However, this will be largely dependent on the innovation of long-term monitoring techniques in both operating and planned pilot projects $[189,190]$.

\section{Conclusions}

(1) Many countries have participated in activities to tackle global climate changes during the last few years. The total $\mathrm{CO}_{2}$ emissions for China in 2005 were $59.76 \times 10^{8}$ tonnes, accounting for $80.03 \%$ of the greenhouse gas emission of China in 2016. To perform its social responsibility, China plans to reduce its $\mathrm{CO}_{2}$ emission per unit of GDP by $40 \%-45 \%$ in 2020 compared with the 2005 level. Therefore, on one hand, China needs to change its current energy framework by reducing the consumption of fossil fuels like coal energy, or applying a clean coal program, capturing the $\mathrm{CO}_{2}$ produced by the combustion of coal. On the other hand, China needs to develop the renewable energy sector, including wind energy, solar energy, and geothermal energy.

(2) The serious air pollution problems in recent years are forcing the government of China to pay more attention to the development of green and clean energy aimed at saving energy and reducing the emissions of greenhouse gases. Some local governments have increased their investment in modern coal-fired power station coupled with the CCS technology. The CCUS engineering projects, especially those related to EOR, are also developing fast.

(3) Traditional CCS projects can store a large amount of $\mathrm{CO}_{2}$, captured from large-scale point source emission sites, deep underground, thus effectively decreasing emissions in the atmosphere. CCUS is more attractive than the CCS technology in China because of the economic benefits accrued by using the $\mathrm{CO}_{2}$. China has large reserves of low permeable oil and gas reservoirs. The conventional water injection methods cannot achieve good production efficiency in such reservoirs; therefore the $\mathrm{CO}_{2}$-EOR and $\mathrm{CO}_{2}$-EGR will have a great potential in enhancing the recovery of oil and natural gas in low and ultralow permeable reservoirs, as well as storing $\mathrm{CO}_{2}$ in the underground space. The CCUS technology will play a considerable role in controlling the reduction of $\mathrm{CO}_{2}$ emissions related to coal-fired power stations and the coal chemical industry. For a long period of time, coal will remain the main energy source in China; thus CCUS technology is very important for cleansing the coal-based industry. $\mathrm{CO}_{2}$ has the potential to be used in the production of geothermal energy because of its favorable physical properties including large density and small viscosity. In addition, studies on replacing water by supercritical $\mathrm{CO}_{2}$ as the fracturing fluid in the oil/gas/shale gas reservoirs are currently being carried out by many researchers. If this method is proved to be feasible, it will greatly decrease water consumption in the production of shale gas. This is particularly meaningful in the western regions of China where there is lack of groundwater resources.

\section{Nomenclature}

ACCA21: Administrative Center for China's Agenda 21

ADB: $\quad$ Asian Development Bank

CAS: $\quad$ Chinese Academy of Sciences

CCERC: China-U.S. Clean Energy Research Center

CCS: Carbon capture, sequestration, or storage

CCTV: China Central Television

CFHEG: Center for Hydrogeology and

Environmental Geology of Chinese

Geological Survey

CCUS: $\quad$ Carbon capture, sequestration, and utilization

CLEAN: $\quad \mathrm{CO}_{2}$ Large-scale Enhanced Gas Recovery project in the Altmark Natural Gas Field

CNOOC: China National Offshore Oil Corporation

CNPC: China National Petroleum Corporation

$\mathrm{CO}_{2}$-AGES: $\mathrm{CO}_{2}$ aided geothermal extraction system

$\mathrm{CO}_{2}$-ECBM: $\mathrm{CO}_{2}$ enhanced coalbed methane recovery

$\mathrm{CO}_{2}$-EGR: $\quad \mathrm{CO}_{2}$ enhanced gas recovery

$\mathrm{CO}_{2}$-EOR: $\quad \mathrm{CO}_{2}$ enhanced oil recovery

$\mathrm{CO}_{2}$-ESG: $\quad \mathrm{CO}_{2}$ enhanced shale gas recovery

CRS: Chromium Reducible Sulfur recovery technology

CSLF: $\quad$ The Carbon Sequestration Leadership Forum

CUCMC: China United Coalbed Methane

Corporation, Ltd

DFZ: Deutsche Friesenpferdezuchter

DEFRA: UK Department for Environment, Food and Rural Affairs

FCC: $\quad$ Fume from Catalytic Cracking

GCCSI: Global Carbon Capture and Storage Institute

GDP: Gross Domestic Product

IEO: International Energy Outlook

IGCC: Integrated Gasification Combined Cycle (IGCC)

IPCC: Intergovernmental Panel on Climate Change

K12B: $\quad$ K12B gas field located at the North Sea

MOST: $\quad$ The Ministry of Science and Technology of China

NSFC: $\quad$ The National Natural Science Foundation of China

NZEC: China-EU Cooperation on Near Zero Emissions Coal project

RECOPOL: Reduction of $\mathrm{CO}_{2}$ emission by means of $\mathrm{CO}_{2}$ storage in coal seams in the Silesian Coal Basin of Poland

SNG-EOR: Synthetic Natural Gas-Enhanced Oil Recovery

USDOE: United States Department of Energy. 


\section{Conflicts of Interest}

The authors hereby declare that there are no conflicts of interest regarding the publication of this paper.

\section{Acknowledgments}

The authors would like to extend their gratitude to the National Natural Science Foundation of China (Grant no. NSFC51374147) and China CDM Fund "Update of China's CCUS Technical Roadmap" (Grant no. 2013085) for funding this work. Q. Li acknowledges financial support from the China-Australia Geological Storage of $\mathrm{CO}_{2}$ (CAGS) Project funded by the Australian Government under the auspices of the Australia China Joint Coordination Group on Clean Coal Technology.

\section{References}

[1] D. Best and E. Levina, "Facing the development of coal in China in the future-prospects and challenges of $\mathrm{CO}_{2}$ capture and sequestration technologies," OECD/IEA2012, 2012.

[2] H. Liu and K. S. Gallagher, "Driving Carbon Capture and Storage forward in China," in Proceedings of the 9th International Conference on Greenhouse Gas Control Technologies, GHGT-9, pp. 3877-3884, November 2008.

[3] Q. Li, Y.-N. Wei, and Y. Dong, "Coupling analysis of China's urbanization and carbon emissions: example from Hubei Province," Natural Hazards, vol. 81, no. 2, pp. 1333-1348, 2016.

[4] G. J. Zheng, F. K. Duan, H. Su et al., "Exploring the severe winter haze in Beijing: the impact of synoptic weather, regional transport and heterogeneous reactions," Atmospheric Chemistry and Physics, vol. 15, no. 6, pp. 2969-2983, 2015.

[5] B. Cai, W. Yang, D. Cao, L. Liu, Y. Zhou, and Z. Zhang, "Estimates of China's national and regional transport sector CO 2 emissions in 2007," Energy Policy, vol. 41, pp. 474-483, 2012.

[6] B. Cai and L. Zhang, "Urban CO2 emissions in China: Spatial boundary and performance comparison," Energy Policy, vol. 66, pp. 557-567, 2014.

[7] H. Xie, X. Li, Z. Fang et al., "Carbon geological utilization and storage in China: Current status and perspectives," Acta Geotechnica, vol. 9, no. 1, pp. 7-27, 2014.

[8] Z. Liu, "Chinas carbon emissions Report 2015," in Proceedings of the Belfer Center for Science and International Affairs, pp. 1-15, Harvard Kennedy School, 2015.

[9] X. Li, N. Wei, Y. Liu, Z. Fang, R. T. Dahowski, and C. L. Davidson, "CO2 point emission and geological storage capacity in China," in Proceedings of the 9th International Conference on Greenhouse Gas Control Technologies, GHGT-9, pp. 2793-2800, November 2008.

[10] Q. Li, J.-T. Zhang, L. Jia et al., "How to "capture the future by utilization of the past" in the coming revision of China CO2 technology roadmap?" in Proceedings of the 12th International Conference on Greenhouse Gas Control Technologies, GHGT 2014, pp. 6912-6916, October 2014.

[11] ACCA21-The Administrative Center for China's Agenda 21., A report on $\mathrm{CO}_{2}$ utilization technologies assessment in China, Science Press, Beijing, China, 2015.

[12] IPCC., "IPCC special report on $\mathrm{CO}_{2}$ capture and storage," pp. 1-431, Cambridge University Press, London, UK, 2005.
[13] S. Sun, "Geological issues related with $\mathrm{CO}_{2}$ geological storage and its meaning on mitigating the climate change," China Basic Science, vol. 3, pp. 17-22, 2006 (Chinese).

[14] CSLF., "Estimation of $\mathrm{CO}_{2}$ storage capacity in geological media," pp. 1-43, 2007.

[15] "Carbon sequestration Atlas of United States and Canada," pp. 1-88, USDOE (U.S. Department of Energy, Office of Fossil Energy), 2007.

[16] S. S. Xu and S. W. Gao, "CO 2 capture from the coal-fired power station and storage technology," Shanghai Energy Conservation, vol. 9, pp. 8-13, 2009 (Chinese).

[17] M. Bai, K. Song, Y. Li, J. Sun, and K. M. Reinicke, “Development of a novel method to evaluate well integrity during $\mathrm{CO}_{2}$ underground storage," SPE Journal, vol. 20, pp. 628-641, 2014.

[18] M. Bai, J. Sun, K. Song, L. Li, and Z. Qiao, "Well completion and integrity evaluation for CO2 injection wells," Renewable and Sustainable Energy Reviews, vol. 45, pp. 556-564, 2015.

[19] M. Bai, J. Sun, K. Song, K. M. Reinicke, and C. Teodoriu, "Evaluation of mechanical well integrity during $\mathrm{CO} 2$ underground storage," Environmental Earth Sciences, vol. 73, no. 11, article no. 7, pp. 6815-6825, 2015.

[20] ACCA21-The Administrative Center for China's Agenda 21, Center for Hydrogeology and Environmental Geology (CFHEG), CGS, "Guidance for site selection of $\mathrm{CO}_{2}$ geological storage in China" Geological Press, Beijing, China, 2012.

[21] ACCA21-Administrative Center for China's Agenda 21, Center for Hydrogeology and Environmental Geology, "Research on the guideline for site selection of $\mathrm{CO}_{2}$ geological storage in China" Geological Publishing House, Beijing, China 2012.

[22] S. Bachu, "Screening and ranking of sedimentary basins for sequestration of $\mathrm{CO} 2$ in geological media in response to climate change," Environmental Geology, vol. 44, no. 3, pp. 277-289, 2003.

[23] CO2CRC., "site selection and characterization for $\mathrm{CO}_{2}$ storage projects," Cooperative Research Centre for Greenhouse Gas Technologies RPT08-1001, Camberra, Australia, 2008.

[24] DOE., "Site screening, selection and initial characterization for storage of $\mathrm{CO}_{2}$ in deep geologic formations," Report, pp. 1-3, 2013.

[25] S. Q. Zhang, J. Q. Guo, X. F. Li, J. J. Fan, and Y. J. Diao, Geological conditions of $\mathrm{CO}_{2}$ sequestration and geological assessment of site selection in China, Geological Publishing House, Beijing, China, 2011.

[26] H. Liu, Z. Hou, X. Li, N. Wei, X. Tan, and P. Were, "A preliminary site selection system for a CO2-AGES project and its application in China," Environmental Earth Sciences, vol. 73, no. 11, article no. 10, pp. 6855-6870, 2015.

[27] Q. Li and K. Ito, "Numerical analysis and modeling of coupled thermo-hydro-mechanical (THM) phenomena in double porous media," in Aquifers: Formation, Transport and Pollution, R. H. Laughton, Ed., pp. 403-413, Nova Science Publishers, New York, NY, USA, 2010.

[28] K. Regenauer-Lieb, M. Veveakis, T. Poulet et al., "Multiscale coupling and multiphysics approaches in earth sciences: Theory," Journal of Coupled Systems and Multiscale Dynamics, vol. 1, pp. 49-73, 2013.

[29] H. Liu, Z. Hou, P. Were, Y. Gou, and X. Sun, "Numerical investigation of the formation displacement and caprock integrity in the Ordos Basin (China) during CO2 injection operation," Journal of Petroleum Science and Engineering, vol. 147, pp. 168180, 2016. 
[30] J. Rutqvist, Y.-S. Wu, C.-F. Tsang, and G. Bodvarsson, "A modeling approach for analysis of coupled multiphase fluid flow, heat transfer, and deformation in fractured porous rock," International Journal of Rock Mechanics and Mining Sciences, vol. 39, no. 4, pp. 429-442, 2002.

[31] O. Stephansson, J. A. Hudson, and L. Jing, "Coupled thermohydro-mechanical-chemical processes in geo-systems: fundamentals, modeling, experiments and applications," pp. 1-803, Elsevier, Inc., Oxford, UK, 2004.

[32] J. Taron, K.-B. Min, H. Yasuhara, K. Trakoolngam, and D. Elsworth, "Numerical simulation of coupled thermo-hydrochemo-mechanical processes through the linking of hydrothermal and solid mechanics codes," in Proceedings of the 41st US Symposiumon Rock Mechanics, Colombia, South America, June 2006.

[33] R. Ganjdanesh, G. A. Pope, and K. Sepehrnoori, "Production of energy from saline aquifers: A method to offset the energy cost of carbon capture and storage," International Journal of Greenhouse Gas Control, vol. 34, pp. 97-105, 2015.

[34] Z. Liu, Carbon emissions in China, Springer Thesis, SpringerVerlag, Berlin, Germany, 2016.

[35] GCCSI., The global status of CCS 2012, Global CCUS Institute, Canberra, Australia, 2012.

[36] W. G. Liang and Y. S. Zhao, "Investigation on carbon dioxide geologic sequestration in salt caverns," Chinese Journal of Underground Space and Engineering, vol. 3, no. 8, pp. 1545-1550, 2007 (Chinese).

[37] L.-Z. Xie, H.-W. Zhou, and H.-P. Xie, "Research advance of $\mathrm{CO}_{2}$ storage in rock salt caverns," Rock and Soil Mechanics, vol. 30, no. 11, pp. 3324-3330, 2009 (Chinese).

[38] H. Liu, Z. Hou, P. Were, X. Sun, and Y. Gou, "Numerical studies on $\mathrm{CO}_{2}$ injection-brine extraction process in a low-medium temperature reservoir system," Environmental Earth Sciences, vol. 73, pp. 6839-6854, 2015.

[39] C. Preston, M. Monea, W. Jazrawi et al., "IEA GHG Weyburn $\mathrm{CO}_{2}$ monitoring and storage project," Fuel Processing Technology, vol. 86, no. 14-15, pp. 1547-1568, 2005.

[40] "IEA GHG Weyburn $\mathrm{CO}_{2}$ monitoring and storage project summary report 2000-2004," in Proceedings of the 7th international conference on greenhouse gas control technologies, M. Wilson and M. Monea, Eds., pp. 1-273, Vancouver, Canada, 2004.

[41] Z. Fang, X. C. Li, H. Li, and H. Q. Chen, "Feasibility study of gas mixture enhanced coalbed methane recovery technology," Rock and Soil Mechanics, vol. 31, no. 10, pp. 3223-3229, 2010 (Chinese).

[42] Z. Fang and X. Li, "Experimental study of gas adsorptioninduced coal swelling and its influence on permeability," Disaster Advances, vol. 5, pp. 769-773, 2012.

[43] Z. Fang, X. Li, and L. Huang, "Laboratory measurement and modelling of coal permeability with different gases adsorption," International Journal of Oil, Gas and Coal Technology, vol. 6, no. 5, pp. 567-580, 2013.

[44] M. Godec, G. Koperna, and J. Gale, " $\mathrm{CO}_{2}$-ECBM: a review of its status and global potential," in Proceedings of the 12th International Conference on Greenhouse Gas Control Technologies, GHGT 2014, pp. 5858-5869, October 2014.

[45] R. Puri and D. Yee, "Enhanced Coalbed Methane Recovery," in Proceedings of the SPE Annual Technical Conference and Exhibition, 26, 23 pages, Society of Petroleum Engineers, New Orleans, LA, USA, 1990.
[46] S. H. Tang, Characteristics of coal reservoir in Jincheng area and properties of adsorption-desorption of multiple gases [Ph.D. thesis], China University of Mining \& Technology, Beijing, China, 2001 (Chinese).

[47] X. L. Sun, F. G. Zeng, and H. J. Liu, " $\mathrm{CO}_{2}$ geological storage and enhance natural gas recovery," Bulletin of Science and Technology, vol. 28, no. 10, pp. 11-16, 2012 (Chinese).

[48] X. Sun, F. Zeng, and H. Liu, "CO2-CH4 system mixing properties and enhanced natural gas recovery," International Journal of Digital Content Technology and its Applications, vol. 6, no. 21, pp. 532-541, 2012.

[49] C. W. Byrer and H. D. Guthrie, "Assessment of world coal resources for carbon dioxide $\left(\mathrm{CO}_{2}\right)$ storage potential-while enhancing potential for coalbed methane, US Department of Energy, Greenhouse Gas Mitigation, Technologies for Activities Implemented Jointly," in Proceedings of Technologies for Activities Implemented Jointly, pp. 573-576, Vancouver, Canada, 1997.

[50] C. W. Byrer and H. D. Guthrie, "Carbon dioxide potential in coalbeds: a near-term consideration for the fossil energy industry , US Department of Energy," in Proceedings of the 23rd International Technical Conference on Coal Utilization and Fuel Systems, pp. 593-600, Clearwater, FL, USA, 1998.

[51] S. H. Stevens and D. Spector, "Enhanced coalbed methane recovery: worldwide applications and $\mathrm{CO}_{2}$ storage potential," Report prepared for IEA Greenhouse Gas R\&D Programme, IEA/CON/97/27, 1998.

[52] S. H. Stevens, J. A. Kuuskraa, and D. Spector, " $\mathrm{CO}_{2}$ storage in deep coal seams: pilot results and worldwide potential," in Fourth International Conference on Greenhouse Gas Control Technologies, Interlaken, Switzerland, 1998.

[53] J. Ye, S. Feng, Z. Fan et al., "Micro-pilot test for enhanced coalbed methane recovery by injecting carbon dioxide in south part of Qinshui Basin," Acta Petrolei Sinica, vol. 28, pp. 77-80, 2007.

[54] M. J. van der Burgt, J. Cantle, and V. K. Boutkan, "Carbon dioxide disposal from coal-based IGCC's in depleted gas fields," Energy Conversion and Management, vol. 33, no. 5-8, pp. 603610, 1992.

[55] S. A. Jikich, D. H. Smith, W. N. Sams, and G. S. Bromhal, "Enhanced gas recovery (EGR) with carbon dioxide sequestration: a simulation study of effects of injection strategy and operational parameters," in Proceedings of the SPE Eatern Meeting Conference and Exhibition, Society of Petroleum Engineers, 2003.

[56] Z. Hou, Y. Gou, J. Taron, U. J. Gorke, and O. Kolditz, “Thermohydro-mechanical modeling of carbon dioxide injection for enhanced gas-recovery (CO 2-EGR): A benchmarking study for code comparison," Environmental Earth Sciences, vol. 67, no. 2, pp. 549-561, 2012.

[57] Y. Gou, Z. Hou, H. Liu, L. Zhou, and P. Were, "Numerical simulation of carbon dioxide injection for enhanced gas recovery (CO2-EGR) in Altmark natural gas field," Acta Geotechnica, vol. 9, no. 1, pp. 49-58, 2014.

[58] S. Kalra and X. Wu, "CO 2 injection for enhanced gas recovery," in Proceedings of the SPE Western North American and Rocky Mountain Joint Meeting, Society of Petroleum Engineers, 2014.

[59] M. Kühn, M. Streibel, N. Nakaten, and T. Kempka, "Integrated underground gas storage of $\mathrm{CO}_{2}$ and $\mathrm{CH}_{4}$ to decarbonise the "power-to-gas-to-gas-to-power" technology," Energy Procedia, vol. 59, pp. 9-15, 2014.

[60] Y. Gou, Z. Hou, M. Li, W. Feng, and H. Liu, "Coupled thermohydro-mechanical simulation of $\mathrm{CO} 2$ enhanced gas recovery 
with an extended equation of state module for TOUGH2MPFLAC3D," Journal of Rock Mechanics and Geotechnical Engineering, vol. 8, no. 6, pp. 904-920, 2016.

[61] T. Clemens, S. Secklehner, K. Mantatzis, and B. Jacobs, "Enhanced gas recovery-challenges shown at the example of three gas fields," in Proceedings of the SPE EUROPEC/EAGE Annual Conference and Exhibition, Society of Petroleum Engineers, 2010.

[62] C. M. Oldenburg, K. Pruess, and S. M. Benson, "Process modeling of $\mathrm{CO}_{2}$ injection into natural gas reservoirs for carbon sequestration and enhanced gas recovery," Energy \& Fuels, vol. 15, no. 2, pp. 726-730, 2001.

[63] C. M. Oldenburg and S. M. Benson, " $\mathrm{CO}_{2}$ Injection for Enhanced Gas Production and Carbon Sequestration," in Proceedings of the 2002 SPE International Petroleum Conference and Exhibition in Mexico, 2002.

[64] S. Polak and A.-A. Grimstad, "Reservoir simulation study of $\mathrm{CO} 2$ storage and $\mathrm{CO} 2$-EGR in the Atzbach-Schwanenstadt gas field in Austria," in Proceedings of the 9th International Conference on Greenhouse Gas Control Technologies, GHGT-9, pp. 2961-2968, November 2008.

[65] M. Kühn, M. Tesmer, P. Pilz et al., "CLEAN: Project overview on CO 2 large-scale enhanced gas recovery in the Altmark natural gas field (Germany)," Environmental Earth Sciences, vol. 67, no. 2, pp. 311-321, 2012.

[66] T. Maldal and I. M. Tappel, "CO2 underground storage for Snøhvit gas field development," Energy, vol. 29, no. 9-10, pp. 1403-1411, 2004.

[67] S. Solomon, M. Carpenter, and T. A. Flach, "Intermediate storage of carbon dioxide in geological formations: A technical perspective," International Journal of Greenhouse Gas Control, vol. 2, no. 4, pp. 502-510, 2008.

[68] D. S. Hughes, "Carbon storage in depleted gas fields: Key challenges," in Proceedings of the 9th International Conference on Greenhouse Gas Control Technologies, GHGT-9, pp. 3007-3014, November 2008.

[69] V. Becker, A. Myrttinen, P. Blum, R. Van Geldern, and J. A. C. Barth, "Predicting 813 CDIC dynamics in CCS: A scheme based on a review of inorganic carbon chemistry under elevated pressures and temperatures," International Journal of Greenhouse Gas Control, vol. 5, no. 5, pp. 1250-1258, 2011.

[70] J. Ennis-King, T. Dance, J. Xu et al., "The role of heterogeneity in $\mathrm{CO} 2$ storage in a depleted gas field: History matching of simulation models to field data for the CO2CRC Otway Project, Australia," in Proceedings of the 10th International Conference on Greenhouse Gas Control Technologies, pp. 34943501, September 2010.

[71] M. Kühn, A. Förster, J. Großmann et al., "CLEAN: Preparing for a CO2-based enhanced gas recovery in a depleted gas field in Germany," in Proceedings of the 10th International Conference on Greenhouse Gas Control Technologies, pp. 55205526, September 2010.

[72] V. Rouchon, C. Magnier, D. Miller, C. Bandeira, R. Gonçalves, and R. Dino, "The relationship between $\mathrm{CO} 2$ flux and gas composition in soils above an EOR-CO2 oil field (Brazil): A guideline for the surveillance of $\mathrm{CO} 2$ storage sites," in Proceedings of the 10th International Conference on Greenhouse Gas Control Technologies, pp. 3354-3362, September 2010.

[73] J. Underschultz, C. Boreham, T. Dance et al., " $\mathrm{CO}_{2}$ storage ina depleted gas field: an overview of the CO2CRC Otway Project and initial results," International Journal of Greenhouse Gas Control, vol. 5, no. 4, pp. 922-932, 2011.
[74] R. J. Arts, V. P. Vandeweijer, C. Hofstee et al., “The feasibility of $\mathrm{CO}_{2}$ storage in the depleted P18-4 gas field offshore the Netherlands (the ROAD project)," International Journal of Greenhouse Gas Control, vol. 11S, pp. S10-S20, 2012.

[75] F. Bilgili, E. Koçak, Ü. Bulut, and M. N. Sualp, "How did the US economy react to shale gas production revolution? An advanced time series approach," Energy, vol. 116, pp. 963-977, 2016.

[76] "Special Report on Carbon Dioxide Capture and Storage," in IPCC (Intergovernmental Panel on Climate Change), B. Metz, O. Davidson, de. Coninck, M. Loos, L. A. Meyer, and H. C. de Coninck, Eds., Cambridge University Press, Cambridge, UK, 2005.

[77] K. C. Schepers, B. Nuttall, A. Y. Oudinot, and R. Gonzalez, Reservoir Modeling And Simulation of The Devonian Gas Shale of Eastern Kentucky for Enhanced Gas Recovery and $\mathrm{CO}_{2}$ Storage, 2009.

[78] C. Ou and Y. Zeng, "Research prospect of $\mathrm{CO}_{2}$ sealing up for safekeeping and $\mathrm{CO}_{2}$ enhanced $\mathrm{CH} 4$ recovery in adsorption reservoir bed," Chemical Industry and Engineering Progress, vol. 30, pp. 258-63, 2011.

[79] H. Wang, Z. Shen, and G. Li, "Feasibility analysis on shale gas exploitation with supercritical $\mathrm{CO}_{2}$," Petroleum Drilling Techniques, vol. 39, pp. 30-35, 2011.

[80] F. Liu, P. Lu, C. Griffith et al., "CO 2-brine-caprock interaction: Reactivity experiments on Eau Claire shale and a review of relevant literature," International Journal of Greenhouse Gas Control, vol. 7, pp. 153-167, 2012.

[81] P. Pei, K. Ling, J. He, and Z. Liu, "Shale gas reservoir treatment by a CO2-based technology," Journal of Natural Gas Science and Engineering, vol. 26, pp. 1595-1606, 2015.

[82] P. C. Harris, R. J. Haynes, and J. P. Egger, "Use of $\mathrm{CO}_{2}$-based fracturing fluids in the red fork formation in the anadarko basin," Society of Petroleum Engineers of AIME, pp. 1003-1008, 1984.

[83] R. Mazza, "Liquid-free stimulations - $\mathrm{CO}_{2} \backslash$ sand dry-frac", in Proceedings of the Conference of Emerging Technologies for Natural Gas Industry, 1997, http://www.netl.doe.gov/KMD/cds/ Disk28/NG10-5.PDF.

[84] D. Gupta, "Nonconventional fracturing fluids," in Proceedings of the SPE Hydraulic Fracturing Technology Conference, The Woodlands, TX, USA, 2009.

[85] T. Ishida, K. Aoyagi, T. Niwa et al., "Acoustic emission monitoring of hydraulic fracturing laboratory experiment with supercritical and liquid $\mathrm{CO}_{2}$," Geophysical Research Letters, vol. 39, no. 16, Article ID L16309, 2012.

[86] H. Wang, G. Li, and Z. Shen, "A feasibility analysis on shale gas exploitation with supercritical carbon dioxide," Energy Sources, Part A: Recovery, Utilization and Environmental Effects, vol. 34, no. 15, pp. 1426-1435, 2012.

[87] K. Breede, K. Dzebisashvili, X. Liu, and G. Falcone, "A systematic review of enhanced (or engineered) geothermal systems: past, present and future," Geothermal Energy, vol. 1, no. 1, article no. $4,2013$.

[88] D. W. Brown, "A hot dry rock geothermal energy concept using supercritical $\mathrm{CO}_{2}$ instead of water," in Proceedings of the 25th Workshop on Geothermal Reservoir Engineering, pp. 233-238, 2000.

[89] K. Pruess, "Enhanced geothermal systems (EGS) using $\mathrm{CO}_{2}$ as working fluid-a novel approach for generating renewable energy with simultaneous sequestration of carbon," Geothermics, vol. 35, no. 4, pp. 351-367, 2006. 
[90] K. Pruess, Enhanced geothermal systems (EGS) comparing water with $\mathrm{CO}_{2}$ as heat transmission fluids, Paper LBNL 63627, 2007.

[91] J. B. Randolph and M. O. Saar, "Impact of reservoir permeability on the choice of subsurface geothermal heat exchange fluid: $\mathrm{CO}_{2}$ versus water and native brine," in Proceedings of the geothermal resources council 35th annual meeting, San Diego, CA, USA, 2011.

[92] T. A. Buscheck, M. Chen, Y. Sun, Y. Hao, and T. R. Elliot, "Two-Stage, Integrated, Geothermal- $\mathrm{CO}_{2}$ Storage Reservoirs: An Approach for Sustainable Energy Production, $\mathrm{CO}_{2}$-Sequestration Security, and Reduced Environmental Risk," Tech. Rep. LLNL-TR-526952, 2012.

[93] C. Xu, P. Dowd, and Q. Li, "Carbon sequestration potential of the Habanero reservoir when carbon dioxide is used as the heat exchange fluid," Journal of Rock Mechanics and Geotechnical Engineering, vol. 8, no. 1, pp. 50-59, 2016.

[94] J. B. Randolph and M. O. Saar, "Combining geothermal energy capture with geologic carbon dioxide sequestration," Geophysical Research Letters, vol. 38, 2011.

[95] Z. H. Pang, F. T. Yang, and Z. F. Duan, "Status and prospect of $\mathrm{CO}_{2}$ geological storage technology," in Proceedings of the in proceedings of the 2 nd waste underground storage workshop, Dunhuang, China, 2008.

[96] S. A. Hosseini and J.-P. Nicot, "Scoping analysis of brine extraction/ re-injection for enhanced CO 2 storage," Greenhouse Gases: Science and Technology, vol. 2, no. 3, pp. 172-184, 2012.

[97] H. Salimi and K.-H. Wolf, "Integration of heat-energy recovery and carbon sequestration," International Journal of Greenhouse Gas Control, vol. 6, pp. 56-68, 2012.

[98] L. Zhang, J. Ezekiel, D. Li, J. Pei, and S. Ren, "Potential assessment of $\mathrm{CO}_{2}$ injection for heat mining and geological storage in geothermal reservoirs of China," Applied Energy, vol. 122, pp. 237-246, 2014.

[99] R. Ganjdanesh, S. L. Bryant, R. L. Orbach, G. A. Pope, and K. Sepehrnoori, "Coupled carbon dioxide sequestration and energy production from geopressured/geothermal aquifers," SPE Journal, vol. 19, no. 2, pp. 239-248, 2014.

[100] U.S. Energy Information Administration (EIA), "International Energy Outlook 2016”, DOE/EIA-0484, 2016.

[101] U.S. Energy Information Administration (EIA), “Annual Energy Outlook 2016 with projections to 2040”, DOE/EIA-0383, 2016.

[102] D. Sandro, J. C. Wu, Q. Yang, A. D. Hou, and J. D. Lin, Suggestions on realization the targets of shale gas production in China, 2014.

[103] X. Wu, Ed., Carbon Dioxide Capture and Geological Storage: The First Massive Exploration in China, Science Press, Beijing, China, 2013.

[104] Q. Li, X. Liu, L. Du et al., "Economics of acid gas injection with comparison to sulfur recovery in China," in Proceedings of the 11th International Conference on Greenhouse Gas Control Technologies, GHGT 2012, pp. 2505-2510, November 2012.

[105] L.-C. Liu, Q. Li, J.-T. Zhang, and D. Cao, “Toward a framework of environmental risk management for $\mathrm{CO} 2$ geological storage in china: gaps and suggestions for future regulations," Mitigation and Adaptation Strategies for Global Change, vol. 21, no. 2, pp. 191-207, 2016.

[106] Y. Wu, J. C. Carroll, and Q. Li, Eds., Gas Injection for Disposal and Enhanced Recovery, Hardcover, Wiley-Scrivener, New York, NY, USA, 2014.
[107] N. Wei, X. Li, Z. Fang et al., "Regional resource distribution of onshore carbon geological utilization in China," Journal of CO2 Utilization, vol. 11, pp. 20-30, 2014.

[108] S. Q. Zhang, J. Q. Guo, Y. J. Diao et al., “Technical method for selection of $\mathrm{CO}_{2}$ geological storage project sites in deep saline aquifers," Geology in China, vol. 38, no. 6, pp. 1640-1651, 2011 (Chinese).

[109] S. Q. Zhang, J. Q. Guo, and X. F. Li, Basics of $\mathrm{CO}_{2}$ Geological Sequestration in China And Site Selection Geological Evaluation, Geological Press, Beijing, China, 2011.

[110] J. Q. Guo, S. Q. Zhang, Y. J. Diao et al., "Site selection method of $\mathrm{CO}_{2}$ geological storage in deep saline aquifers," Journal of Jilin University (Earth Science Edition), vol. 41, no. 4, pp. 1084-1091, 2011 (Chinese).

[111] J. Q, D. G. Guo, S. Q. Zhang et al., "Potential evaluation of $\mathrm{CO}_{2}$ geological storage and pilot-scale projects," Geological Survey of China, vol. 2, no. 4, pp. 36-46, 2015 (Croatian).

[112] X. F. Jia, Y. Zhang, H. Zhang et al., "Method of target area selection of $\mathrm{CO}_{2}$ geological storage in China," Journal of Jilin University (Earth Science Edition), vol. 4, pp. 255-267, 2014 (Chinese).

[113] X. C. Li and Z. M. Fang, "Status quo of connection technologies of $\mathrm{CO}_{2}$ geological storage in China," Rock and Soil Mechanics, vol. 28, no. 10, pp. 2229-2233, 2007 (Chinese).

[114] Q. Li, X. Li, N. Wei, and Z. Fang, "Possibilities and potentials of geological co-storage CO2 and SO2 in China," in Proceedings of the 10th International Conference on Greenhouse Gas Control Technologies, pp. 6015-6020, September 2010.

[115] X. C. Li, Y. F. Liu, B. Bai, and Z. M. Fang, "Ranking and screening of $\mathrm{CO}_{2}$ saline aquifer storage zones in China," Chinese Journal of Rock Mechanics and Engineering, vol. 25, no. 5, pp. 744-748, 2006 (Chinese).

[116] Y. F. Liu, X. C. Li, and B. Bai, "Preliminary estimation of $\mathrm{CO}_{2}$ storage capacity of the deep saline formations in China," Earth Science- Journal of China University of Geosciences, vol. 25, no. 5, pp. 126-131, 2006 (Chinese).

[117] H. T. Zhang, D. G. Wen, and Y. L. Li, "Analysis of the $\mathrm{CO}_{2}$ geological storage conditions in China and some suggestions," Geological Bulletin of China, vol. 24, no. 12, pp. 1101-1110, 2005 (Chinese).

[118] H. Y. Jiang, P. P. Sheng, X. F. Li et al., "Study into technologies for estimating theoretical volume of $\mathrm{CO}_{2}$ stored underground worldwide," Sino-Global Energy, vol. 13, no. 2, pp. 93-99, 2008 (Chinese).

[119] W. Zhang, Y. L. Li, Y. Zheng, L. Jiang, and G. B. Qiu, " $\mathrm{CO}_{2}$ storage capacity estimation in geological sequestration: issues and research progress," Advances in Earth Science, vol. 23, no. 10, pp. 1061-1069, 2008 (Chinese).

[120] Z. G. Xu, D. Z. Chen, and R. S. Zeng, "Principles of $\mathrm{CO}_{2}$ geological storage and conditions," Journal of Southwest Petroleum University (Science \& Technology Edition), vol. 31, no. 1, pp. 9197, 2009 (Chinese).

[121] Z. Xu, D. Chen, R. Zeng et al., "Geological storage framework of $\mathrm{CO}_{2}$ subsurface burial trial area of daqingzijing block in the jilin oilfield," Acta Geologica Sinica, vol. 83, no. 6, pp. 875-884, 2009 (Chinese).

[122] Y. Z. Yang, P. P. Sheng, X. M. Song, S. Y. Yang, and Y. L. Hu, "Greenhouse gas geo-sequestration mechanism and capacity evaluation in aquifer," Journal of Jilin University (Earth Science Edition), vol. 39, no. 4, pp. 744-748, 2009 (Chinese). 
[123] W. Xu, X. S. Su, S. H. Du et al., "Capacity assessment and uncertainty analysis of $\mathrm{CO}_{2}$ storage in deep saline aquifer in the central depression of Songliao Basin," Quaternary Sciences, vol. 31, no. 3, pp. 483-490, 2011 (Chinese).

[124] C. Guo, L. Pan, K. Zhang, C. M. Oldenburg, C. Li, and Y. $\mathrm{Li}$, "Comparison of compressed air energy storage process in aquifers and caverns based on the Huntorf CAES plant," Applied Energy, vol. 181, pp. 342-356, 2016.

[125] X. K. Ren, Y. J. Cui, X. P. Bu, Y. J. Tang, and J. Q. Zhang, "Analysis on $\mathrm{CO}_{2}$ storage potentiality in Ordos Basin," Energy of China, vol. 32, no. 1, pp. 29-32, 2010 (Chinese).

[126] J. Xie, K. N. Zhang, and L. T. Hu, "Numerical investigation of geological $\mathrm{CO}_{2}$ storage with multiple injection wells for the Shenhua Ordos CCS project," Journal of Beijing Normal University (Natural Science), vol. 51, no. 6, pp. 90-96, 2015 (Chinese).

[127] J. Xie, K. N. Zhang, Y. S. Wang, L. Q. Tan, and C. B. Guo, "Performance assessment of $\mathrm{CO}_{2}$ geological storage in deep saline aquifers in Ordos Basin, China," Rock and Soil Mechanics, vol. 37, no. 1, pp. 166-174, 2016 (Chinese).

[128] B. He, T. F. Xu, Y. L. Yuan et al., "An analysis of the influence factors on $\mathrm{CO}_{2}$ injection capacity in a deep saline formation: a case study of Shiqianfeng Group in the Erdos Basin," Hydrogeology \& Engineering Geology, vol. 43, no. 1, pp. 136-142, 2016.

[129] X. Li, Q. Li, B. Bai, N. Wei, and W. Yuan, "The geomechanics of Shenhua carbon dioxide capture and storage (CCS) demonstration project in Ordos Basin, China," Journal of Rock Mechanics and Geotechnical Engineering, vol. 8, no. 6, pp. 948-966, 2016.

[130] C. Luo, A. L. Jia, T. J. Wei et al., " $\mathrm{CO}_{2}$ storage conditions in the saline formation of the Shanxi Group 2 section in the Zizhou area of the Ordos basin and its capacity estimation," Journal of Northeast Petroleum University, vol. 40, no. 1, pp. 26-36, 2016 (Chinese).

[131] ADB, "Promoting carbon capture utilization and storage through carbon dioxide-enhanced oil recovery in the Peoples Republic of China," p. 16, 2015.

[132] M. Hao and Y. C. Song, "Research status of $\mathrm{CO}_{2}$-EOR technology," Drilling \& Production Technology, vol. 33, pp. 59-63, 2010 (Chinese).

[133] X. G. Dong, P. H. Han et al., Pilot-scale field test of the $\mathrm{CO}_{2}-\mathrm{EOR}$ in Daqing oilfield, Petroleum Industry Press, Beijing, China, 1999.

[134] P. Guo, S. Y. Zhang, Y. Wu et al., "The minimum miscible pressure of $\mathrm{CO}_{2}$ flooding in Dagang oilfield," Journal of Southwest Petroleum University (Science \& Technology Edition), vol. 21, no. 3, pp. 19-21, 1999 (Chinese).

[135] H. Y. Jiang, P. P. Shen, and T. X. Zhong, "The relationship between $\mathrm{CO}_{2}$ geological storage and enhanced oil recovery," Petroleum Geology and Recovery Efficiency, vol. 15, no. 6, pp. 5255, 2008 (Chinese).

[136] P. P. Shen and X. W. Liao, $\mathrm{CO}_{2}$ geological storage and enhance oil recovery, Petroleum Industry Press, Beijing, China, 2009.

[137] H. J. Yu, G. J. Zhu, and J. Tian, "EOR by $\mathrm{CO}_{2}$ injection into offshore heavy oil-cap reservoir with strong edge and bottom waters," Petroleum Geology \& Oilfield Development in Daqing, vol. 32, no. 5, pp. 137-142, 2013 (Chinese).

[138] X. A. Yue, R. B. Zhao, and F. L. Zhao, Technological Challenges for $\mathrm{CO}_{2}$ EOR in China, Science paper online, 2007.

[139] B. W. Guo, "Characteristics of tectonic coal and analysis on the location of $\mathrm{CO}_{2}$," Coal Geology \& Exploration, vol. 29, no. 1, pp. 28-30, 2001 (Chinese).
[140] L. Zhou, Q. Y. Feng, and X. D. Li, "Mechanism and application potential of geological sequestration of carbon dioxide in deep coal seams," Earth and Environment, vol. 35, no. 1, pp. 9-14, 2007 (Chinese).

[141] Q. Li, W. Fei, X. Liu, X. Wei, M. Jing, and X. Li, "Challenging combination of $\mathrm{CO} 2$ geological storage and coal mining in the Ordos basin, China," Greenhouse Gases: Science and Technology, vol. 4, no. 4, pp. 452-467, 2014.

[142] J. Yang, "Studies on the injection of $\mathrm{CO}_{2}$ into coalbed reservoir," Petrochemical Industry Application, vol. 12, pp. 26-28, 2015 (Chinese).

[143] L. Hou, J. J. Tian, and Y. X. Zhang, "Numerical simulation on geological sequestration of $\mathrm{CO}_{2}$ and coalbed methane displacement," Shanxi Coal, vol. 1, pp. 78-81, 2016 (Chinese).

[144] K. Jiang, Z. P. Li, H. E. Dou, Z. Y. Cao, and G. Hong, "Potential evaluation model of $\mathrm{CO}_{2}$ geological storage in Qinshui basin," Special Oil and Gas Reservoirs, vol. 23, no. 2, pp. 116-118, 2016 (Chinese).

[145] J. Shen, Y. Qin, C.-J. Zhang, Q.-J. Hu, and W. Chen, "Feasibility of enhanced coalbed methane recovery by $\mathrm{CO}_{2}$ sequestration into deep coalbed of Qinshui Basin," Journal of China Coal Society, vol. 41, no. 1, pp. 156-161, 2016 (Chinese).

[146] S.-H. Tang, D.-Z. Tang, and Q. Yang, "Variation regularity of gas component concentration in binary-component gas adsorption-desorption isotherm experiments," Journal of China University of Mining \& Technology, vol. 33, no. 4, pp. 448-452, 2004 (Chinese).

[147] S. H. Tang, D. Z. Tang, and Q. Yang, "Binary-component gas adsorption isotherm experiments and their significance to exploitation of coalbed methane," Earth Science- Journal of China University of Geosciences, vol. 29, no. 2, pp. 219-22, 2004.

[148] H. G. Yu, Study of characteristics and prediction of $\mathrm{CH}_{4}, \mathrm{CO}_{2}, \mathrm{~N}_{2}$ and binary GAS adsorption on coals and $\mathrm{CO}_{2} / \mathrm{CH}_{4}$ replacement, Shandong University of Science and Technology, Qingdao, China, 2005.

[149] W. P. Jiang, Y. J. Cui, Q. Zhang, and Y. H. Li, “The quantum chemical study on the coal surface interacting with $\mathrm{CH}_{4}$ and $\mathrm{CO}_{2}$," Journal of China Coal Society, vol. 31, no. 2, pp. 237-242, 2006 (Chinese).

[150] W. Z. Wu, Characteristics of the inert group structure of the coal in Shendong and the molecular simulation of its reaction with $\mathrm{CH}_{4}$ [M. S., thesis], Taiyuan University of Technology, 2010 (Chinese).

[151] W. B. Fei, Q. Li, X. C. Wei, R. R. Song, M. Jing, and X. C. $\mathrm{Li}$, "Interaction analysis for $\mathrm{CO}_{2}$ geological storage and underground coal mining in Ordos Basin, China," Engineering Geology, vol. 196, pp. 194-209, 2015.

[152] J. P. Ye, Y. Qin, and D. Y. Lin, Coalbed methane resources in China, China University of Mining \& Technology Press, Xuzhou, China, 1998.

[153] Y. F. Liu, X. C. Li, and B. Bai, "Preliminary estimation of $\mathrm{CO}_{2}$ storage capacity of coalbeds in China," Chinese Journal of Rock Mechanics and Engineering, vol. 24, no. 16, pp. 2947-2952, 2005 (Chinese)

[154] Y. F. Liu, X. C. Li, Z. M. Fang, and B. Bai, "Preliminary estimation of $\mathrm{CO}_{2}$ storage capacity of gas reservoirs in China," Rock and Soil Mechanics, vol. 27, no. 12, pp. 2277-2281, 2006.

[155] D. Z. Dong, C. N. Zou, H. Yang et al., "Progress and prospects of shale gas exploration and development in China," Acta Petrolei Sinica, vol. 33, supplement 1, pp. 107-114, 2012 (Chinese). 
[156] Y. S. Zhu, X. X. Song, Y. T. Guo et al., "High-pressure adsorption characteristics and controlling factors of $\mathrm{CH}_{4}$ and $\mathrm{CO}_{2}$ on shales from Longmaxi formation, Chongqing, Sichuan Basin," Natural Gas Geoscience, vol. 27, pp. 1942-1952, 2016 (Chinese).

[157] T. F. Xu and W. Zhang, "Enhanced geothermal systems: international developments and Chinas prospects," Petroleum Science Bulletin, vol. 1, no. 1, pp. 38-44, 2016 (Chinese).

[158] F. G. Wang, Effect of $\mathrm{CO}_{2}$-EGS-water-rock on the characteristics of formation porosity and permeability, Master thesis at [M, S. thesis], Jilin University, 2013 (Chinese).

[159] F. G. Wang, J. Na, and X. X. Geng, "The impacts of different $\mathrm{CO}_{2}$ injection temperature on heat extraction rate in $\mathrm{CO}_{2}$ enhanced geothermal system: based on the CCS demonstration project in Erdos," Science \& Technology Review, vol. 31, no. 8, pp. 34-39, 2013 (Chinese).

[160] Y. Shi, The operating mechanism and optimization research on carbon dioxide plume geothermal system in Quantou formation of Songliao Basin [Ph.D. thesis], Jilin University, 2014 (Chinese).

[161] Z. Y. Hou, T. F. Xu, B. He, B. Feng, and J. Na, "Laboratory experimental study of dissolution using supercritical $\mathrm{CO}_{2}$ as a stimulation agent for enhanced geothermal system (EGS) in SongLiao basin," in Renewable Energy Resources, vol. 1, pp. 122$128,2016$.

[162] M. Z. Liu, B. Bai, X. C. Li, and rtal, "Experimental study of fracturing characteristics of sandstone under $\mathrm{CO}_{2}$-water twophase condition and effective stress model," Chinese Journal of Rock Mechanics and Engineering, vol. 35, no. 2, pp. 38-47, 2016 (Chinese).

[163] G. Z. Lv, Q. Li, S. Wang, and X. Li, "Key techniques of reservoir engineering and injection-production process for $\mathrm{CO}_{2}$ flooding in China's SINOPEC Shengli oilfield," Journal of $\mathrm{CO}_{2}$ Utilization, vol. 11, pp. 31-40, 2015.

[164] "China United Coalbed Methane Corporation (CUCMC), Ltd," Alberta Research Council, "The pilot-scale field test of $\mathrm{CO}_{2}$ ECBM technology in China" Geological Press, Beijing, China, 2008.

[165] C. H. Qu, "Discussion on developing the technology of $\mathrm{CO}_{2}$ capture and storage," China Science and Technology Periodical Database Industry, vol. 8, pp. 1-3, 2015.

[166] Department of Social Development (DSD), " $\mathrm{CO}_{2}$ capture, utilization and storage technologies in China," The Administrative Center for China's Agenda 21 ACCA21, p. 22, 2010 (Chinese).

[167] Y. K. Du, Study on the mechanism of supercritical carbon dioxide efflux in the rock breaking mechanism [Ph.D. thesis], China University of Petroleum, Huadong, China, 2009 (Chinese).

[168] Q. Fang, $\mathrm{CO}_{2}$ Geological Storage Combined with Brine Production in High-salinity and Low-permeability Aquifers [Ph.D. thesis], China University of Geosciences, Wuhan, China, 2014 (Chinese).

[169] X. H. Zhang, X. B. Lu, and Q. J. Liu, "The effect of the characteristics of Cap on the escaping velocity of $\mathrm{CO}_{2}$," Soil Engineering and Foundation, vol. 23, no. 3, pp. 67-70, 2009 (Chinese).

[170] S. Q. Zhang, Y. J. Diao, X. X. Cheng et al., "geological storage leakage routes and environment monitoring," Journal of Glaciology and Geocryology, vol. 32, no. 6, pp. 1251-1261, 2010 (Chinese).

[171] Q. Li, “The potential environmental impacts and risk studies during $\mathrm{CO}_{2}$ geological storage-safety evaluation," in Workshop on Greenhouse Gas Control and Environmental Impacts Evaluation, Chinese Academy for Environmental Planning, Shamen, p. 20, 2011.
[172] L. H. Peng, J. J. Wang, W. J. You, and L. S. Xu, "Environmental issues and advances of carbon dioxide geological storage," Hydrogeology \& Engineering Geology, vol. 40, no. 5, pp. 104-110, 2013 (Chinese).

[173] H. Shi, L. C. Liu, and Q. Li, "A comparative study of geoenvironmental impacts of $\mathrm{CO}_{2}$ geological storage and high level nuclear waste geo-disposal, China Population," Resources and Environment, vol. 25, pp. 203-207, 2015.

[174] X. Y. Zhang, J. M. Cheng, and J. Liu, "Advances on the research of $\mathrm{CO}_{2}$ sequestration," Hydrogeology \& Engineering Geology, vol. 4, pp. 58-88, 2006 (Chinese).

[175] Z. G. Xu, D. Z. Chen, and R. S. Zeng, "The leakage risk assessment and remediation options of $\mathrm{CO}_{2}$ geological storage," Geological Review, vol. 54, no. 2, pp. 373-385, 2008.

[176] The Climate Group, CCUS in China: 18 hot-spot problems, 2011.

[177] Greengen Corporation Limited, Challenging the global climate changes- $\mathrm{CO}_{2}$ capture and storage, China Water \& Power Press, Beijing, China, 2008.

[178] E. S. Rubin, J. E. Davison, and H. J. Herzog, "The cost of CO2 capture and storage," International Journal of Greenhouse Gas Control, vol. 40, pp. 378-400, 2015.

[179] B. Huang, S. Xu, S. Gao et al., "Industrial test and technoeconomic analysis of $\mathrm{CO} 2$ capture in Huaneng Beijing coalfired power station," Applied Energy, vol. 87, no. 11, pp. 33473354, 2010.

[180] W. Y. Chen, Z. X. Wu, and W. Z. Wang, "The strategy of $\mathrm{CO}_{2}$ capture and storage and its potential effect on the long term reduction in $\mathrm{CO}_{2}$ emission in China," Environmental Science, vol. 28, no. 6, pp. 1178-1179, 2007 (Chinese).

[181] J. Chen, C. Zheng, W. Chen, and W. Y. Fei, “The emergency in reducing the $\mathrm{CO}_{2}$ emission and the development of capture technology," in Proceedings of the in Proceedings of the 10th Annual Meeting of China Association for Science and Technology: reduction in $C O<s u b>2</ s u b>$ emission and its clean utilization and development workshop, pp. 10-13, 2008.

[182] X. Y. Zhang, C. Di, and L. C. Lei, $\mathrm{CO}_{2}$ corrosion and treatment, Chemistry Industry Press, Beijing, China, 2000.

[183] M. J. Wu, "Studies on the corrosion of the ground system in tertiary oil recovery with $\mathrm{CO}_{2}$ flooding and treatment," OilGasfield Surface Engineering, vol. 23, no. 1, pp. 16-18, 2004 (Chinese).

[184] K. van Alphen, Q. van Voorst tot Voorst, M. P. Hekkert, and R. E. H. M. Smits, "Societal acceptance of carbon capture and storage technologies," Energy Policy, vol. 35, no. 8, pp. 4368-4380, 2007.

[185] J. K. Haug and P. Stigson, "Local acceptance and communication as crucial elements for realizing CCS in the Nordic region," in Proceedings of the 8th Trondheim Conference on CO2 Capture, Transport and Storage, TCCS 2015, pp. 315-323, June 2015.

[186] Z. Kapetaki, J. Simjanović, and J. Hetland, "European carbon capture and storage project network: Overview of the status and developments," in Proceedings of the 8th Trondheim Conference on CO2 Capture, Transport and Storage, TCCS 2015, pp. 12-21, June 2015.

[187] Z.-A. Chen, Q. Li, L.-C. Liu et al., "A large national survey of public perceptions of CCS technology in China," Applied Energy, vol. 158, pp. 366-377, 2015.

[188] Q. Li and G. Liu, "Risk assessment of the geological storage of $\mathrm{CO}_{2}$ : a review," in Geologic Carbon Sequestration: Understanding Reservoir Behavior, V. Vishal and T. N. Singh, Eds., pp. 249-284, Springer, New York, NY, USA, 2016. 
[189] Q. Li, Z. A. Chen, J.-T. Zhang, L.-C. Liu, X. C. Li, and L. Jia, "Positioning and revision of CCUS technology development in China," International Journal of Greenhouse Gas Control, vol. 46, pp. 282-293, 2016.

[190] Q. Li, R. Song, X. Liu, G. Liu, and Y. Sun, "Monitoring of carbon dioxide geological utilization and storage in China: a review," in Acid Gas Extraction for Disposal and Related Topics, Y. Wu, J. J. Carroll, and W. Zhu, Eds., pp. 331-358, Wiley-Scrivener, New York, NY, USA, 2016. 

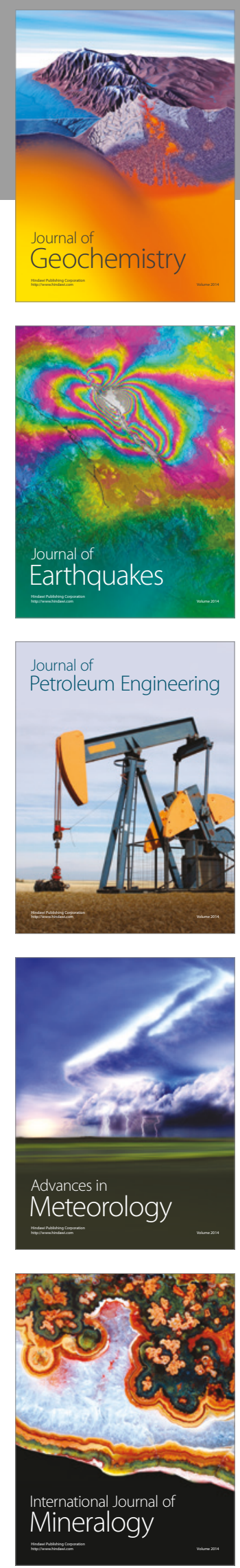
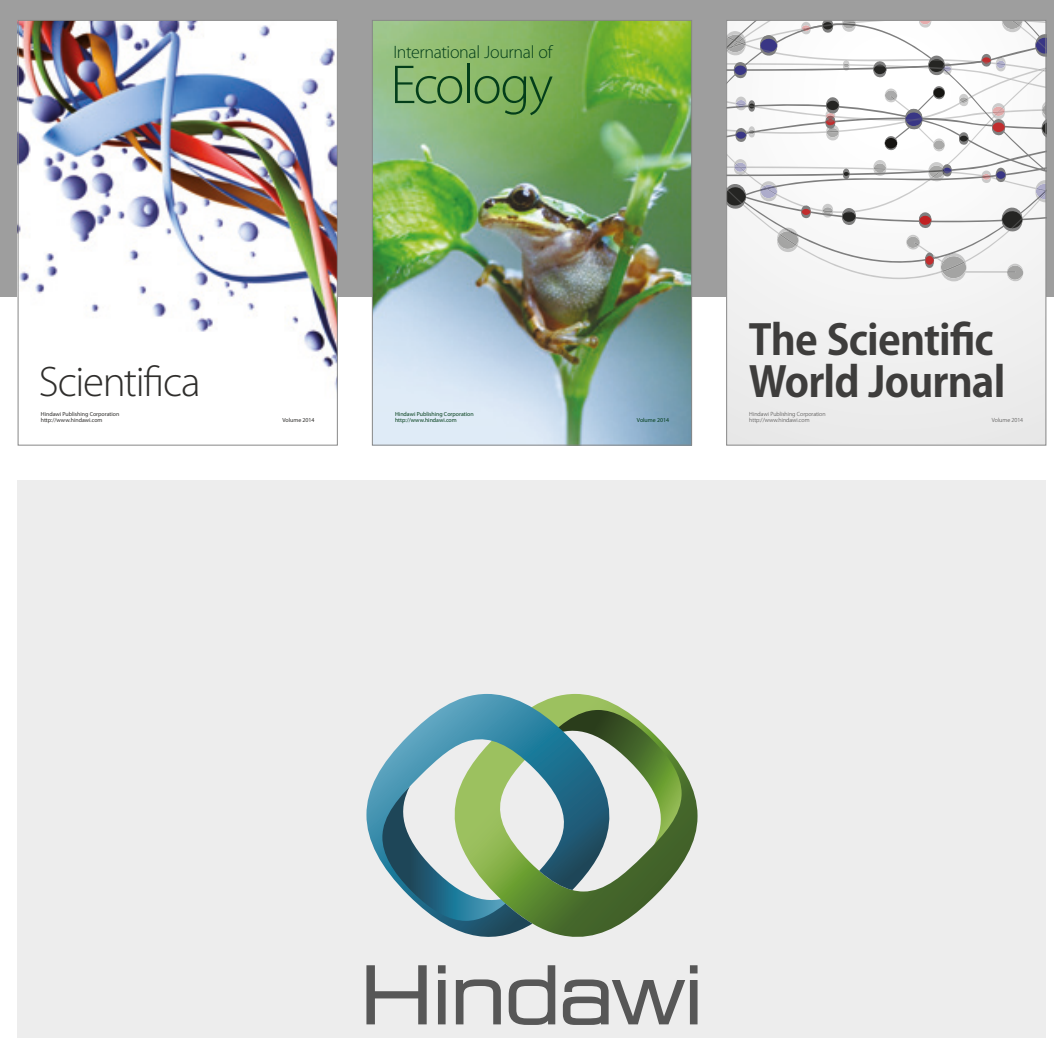

Submit your manuscripts at

https://www.hindawi.com
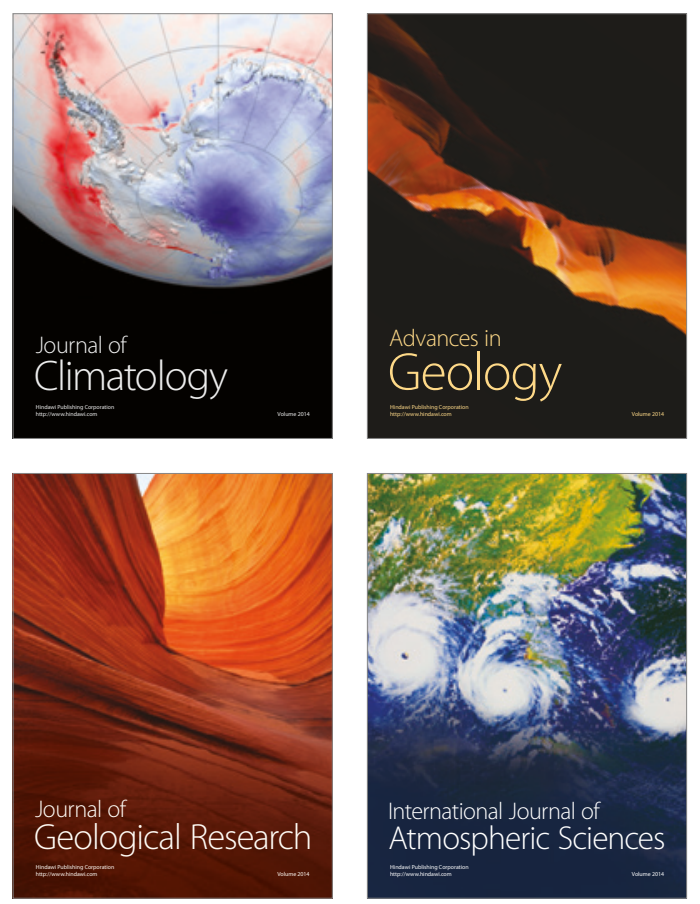

The Scientific

World Journal
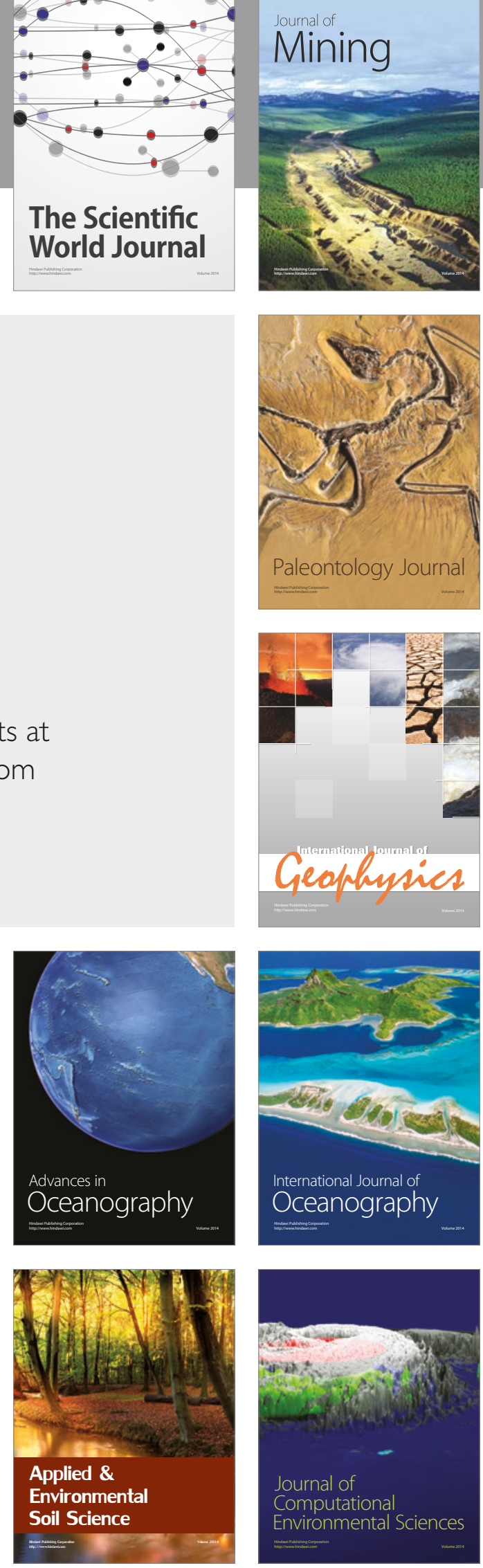